Article

\title{
Revision of Commonly Accepted Warburg Mechanism of Cancer Development: Redox-Sensitive Mitochondrial Cytochromes in Breast and Brain Cancers by Raman Imaging
}

\author{
Halina Abramczyk*(D), Jakub Maciej Surmacki (D), Beata Brozek-Pluska (D) and Monika Kopec \\ Laboratory of Laser Molecular Spectroscopy, Institute of Applied Radiation Chemistry, \\ Lodz University of Technology, Wroblewskiego 15, 93-590 Lodz, Poland; jakub.surmacki@p.lodz.pl (J.M.S.); \\ beata.brozek-pluska@p.lodz.pl (B.B.-P.); monika.kopec@p.lodz.pl (M.K.) \\ * Correspondence: halina.abramczyk@p.lodz.pl; Tel.: +48-426313188
}

Citation: Abramczyk, H.; Surmacki, J.M.; Brozek-Pluska, B.; Kopec, M. Revision of Commonly Accepted Warburg Mechanism of Cancer Development:

Redox-Sensitive Mitochondrial Cytochromes in Breast and Brain Cancers by Raman Imaging. Cancers 2021, 13, 2599. https://doi.org/ 10.3390/cancers13112599

Academic Editors: Martial Guillaud and Bénédicte F. Jordan

Received: 12 March 2021

Accepted: 24 May 2021

Published: 26 May 2021

Publisher's Note: MDPI stays neutral with regard to jurisdictional claims in published maps and institutional affiliations.

Copyright: (c) 2021 by the authors. Licensee MDPI, Basel, Switzerland. This article is an open access article distributed under the terms and conditions of the Creative Commons Attribution (CC BY) license (https:// creativecommons.org/licenses/by/ $4.0 /)$.
Simple Summary: We studied oncogenic processes that characterize human breast cancer (infiltrating ductal carcinoma (IDC)) and human brain tumors: glioma, astrocytoma and medulloblastoma, based on the quantification of cytochrome redox status by exploiting the resonance-enhancement effect of Raman scattering. Our results suggest that the mechanisms controlling the electron transport chain might be deregulated in cancers and indicate that electron transport, organized in terms of electronegativity, is inhibited between complex III and cytochrome $c$ for isolated cells in vitro and between cytochrome $c$ and complex IV in brain and breast tissues. The results provide evidence that the extracellular matrix and interactions with cell microenvironment play an important role in the mechanisms controlling the electron transport chain by cytochrome $c$.

\begin{abstract}
We used Raman imaging to monitor changes in the redox state of the mitochondrial cytochromes in ex vivo human brain and breast tissues, surgically resected specimens of human tissues and in vitro human brain cells of normal astrocytes (NHA), astrocytoma (CRL-1718), glioblastoma (U87-MG) and medulloblastoma (Daoy), and human breast cells of normal cells (MCF 10A), slightly malignant cells (MCF7) and highly aggressive cells (MDA-MB-231) by means of Raman microspectroscopy at $532 \mathrm{~nm}$. We visualized localization of cytochromes by Raman imaging in the major organelles in cancer cells. We demonstrated that the "redox state Raman marker" of the ferric lowspin heme in cytochrome $c$ at $1584 \mathrm{~cm}^{-1}$ can serve as a sensitive indicator of cancer aggressiveness. We compared concentration of reduced cytochrome $c$ and the grade of cancer aggressiveness in cancer tissues and single cells and specific organelles in cells: nucleous, mitochondrium, lipid droplets, cytoplasm and membrane. We found that the concentration of reduced cytochrome $c$ becomes abnormally high in human brain tumors and breast cancers in human tissues. Our results reveal the universality of Raman vibrational characteristics of mitochondrial cytochromes in metabolic regulation in cancers that arise from epithelial breast cells and brain glial cells.
\end{abstract}

Keywords: optical biopsy; Raman spectroscopy and imaging; brain and breast cancer; cytochrome $c$; cell cultures

\section{Introduction}

It is becoming clear that oncogenic processes during cancer development are governed by the balance between the need of the cell for energy supply with its equally important need for macromolecular building blocks and maintenance of redox balance [1-4].

Regarding macromolecular building blocks, the role of fatty acids as critical bioenergetic substrates within the glioma cells [5-12] and breast cells $[9,13,14]$ has been recognized. The redox balance that depends to a large extent on mitochondrial functionality in the electron transfer chain has been extensively studied [15-18]. 
Cytochrome family, a heme-containing protein, plays a critical role in mitochondrial mechanisms of cell respiration as an electron carrier in the electron transfer chain in mechanisms of oxidative phosphorylation. Cytochromes are also important in intercellular cell signaling, metabolism of polyunsaturated fatty acids and apoptosis. Cytochrome $c$ is released into the extracellular space and can be easily measured in the serum, serving as a marker of severe cellular damage and death. Elevated levels of serum cytochrome $c$ have been reported in many diseases, including cancer [18]. The results on the role of cytochrome $c$ in brain disorders of different research groups are somewhat conflicted regarding the respiratory chain in glioma $[15,16]$. Early studies on glioma cell rat xenografts identified lower enzyme expression of Complex IV, also known as cytochrome $c$ oxidase (COX, Complex IV) and SDH (Complex II) enzyme expression in more hypoxic areas of the tumor. More recently, one group reported significantly lower activity of complex II-IV in anaplastic astrocytomas and lower activity of complex I-IV in glioblastomas compared with normal brain tissue [15]. Another group studied human glioma tissue samples by mass spectrometry and observed lower expression of some subunits in Complex I, but higher levels of many oxidative enzymes, including catalase [16].

The significance of mitochondrial dysfunctionality has not been studied by Raman methods, to the best of our knowledge, but traditional biological techniques were used to study invasive ductal carcinoma (IDC) [19].

However, further studies are required for supporting this role for cytochrome $c$, and the responsible pattern recognition receptor(s) remain to be discovered.

Cytochromes are classified on the basis of their lowest electronic energy absorption band in their reduced state. Therefore, we can distinguish cytochrome P450 (450 nm), cytochrome $c(550 \mathrm{~nm})$, cytochromes $b(\approx 565 \mathrm{~nm})$ and cytochromes $a(605 \mathrm{~nm})$. The cytochromes are localized in the electron transport chain in the complex known as complex III or Coenzyme Q-Cyt $C$ reductase, sometimes also called the cytochrome $b c_{1}$ complex (cytochrome $b$, cytochrome $c_{1}$ ). Cytochrome $c$, which is reduced to cytochrome $c \mathrm{Fe}^{2+}$ (ferrous) by the electron from the complex III to complex IV, where it passes an electron to the copper binuclear center, being oxidized back to cytochrome $c$ (cyt c Fe ${ }^{3+}$ (ferric)). Complex IV is the final enzyme of the electron transport system. The complex IV contains two cytochromes, $a$ and $a_{3}$, and two copper centers. Using different excitations being in resonance with the absorption bands of the cytochromes, one can spectrally isolate various cytochrome chromophores in the complex III, cytochrome $c$ and complex IV by resonance Raman enhancement scattering. Using different excitations, we are able to monitor the contribution of the cytochrome family in the electron transfer chain in the mitochondrial respiration originating from cytochrome $b, c_{1}$ in complex III, cytochrome $c$ and $a$ and $a_{3}$ cytochromes in complex IV. The spectral features of cytochromes $a$ and $a_{3}$ in complex IV can be observed at resonance conditions of 420 and $445 \mathrm{~nm}$ for the oxidized and reduced state respectively, as well as at pre-resonance conditions. The spectral features of cytochrome $c$ can be monitored at $532 \mathrm{~nm}$ due to the absorbance band ( $Q$ band) centered at $530 \mathrm{~nm}$ [20].

Monitoring redox state of mitochondrial cytochromes has been demonstrated as a versatile clinical diagnostic tool with numerous successful reports on the detection of cancerous tissues in human patients [19,21-24].

It is evident that the real progress in improved cancer therapy and treatment depends on much better than the current understanding of biological mechanisms of mitochondrial dysfunction in cancer. To achieve this goal, there is an urgent need to improve the conventional methods of molecular biology (immunohistochemistry, real-time PCR, immunoblotting, measurement of mitochondrial membrane potential, cell proliferation assay and caspase 3 activity assay under hypoxic conditions [19]) in cancer diagnostics and develop new imaging tools, because current imaging methods are often limited by inadequate sensitivity, specificity, spatial and spectral resolutions [25].

Our goal was to demonstrate the possibility of monitoring redox state changes occurring in mitochondrial cytochromes in cancers by Raman imaging and correlate the concentration of cytochrome $c$ with cancer aggressiveness. It is well-known that cytochrome $c$ is 
undoubtedly one of the most prominent molecules in the electron transport chain required to fuel life via ATP, but its role in molecular mechanisms associated with an aggressive phenotype of cancer remain largely unclear. Better comprehension of biochemical pathways in two different types of cancer-human brain tumors and ductal cancer cells-can be obtained by an integrated approach consisting of in vitro cells, ex vivo tissues and relevant biological models in vivo.

Therefore, this paper presents a truly unique landscape of cancer modern biochemistry by a non-invasive Raman approach to study redox status of cytochromes in brain and breast cancer in ex vivo surgically resected specimens of human brain and breast, normal and cancerous tissues and in vitro human brain and breast cells.

We study human normal and cancer tissues, in vitro human brain cells of normal astrocytes (NHA), astrocytoma (CRL-1718), glioblastoma (U87-MG), medulloblastoma (Daoy), and human breast normal cells (MCF 10A), slightly malignant cells (MCF7) and highly aggressive cells (MDA-MB-231) by means of Raman microspectroscopy, at $532 \mathrm{~nm}$.

In this paper, we explore a hypothesis involving the role of reduction-oxidation pathways related to cytochrome $c$ in cancer development.

Understanding of cytochrome's role in brain and breast cancers with new methods will help establish Raman spectroscopy as a competitive clinical diagnosis tool for cancer diseases involving mitochondrial dysfunction and is a prerequisite for successful pharmacotherapy.

\section{Materials and Methods}

\subsection{Reference Chemicals}

Cytochrome $c$ (no. C2506) and DL-lactic acid (no. 69785) were purchased from Sigma Aldrich.

\subsection{Patients}

In the presented studies, the total number of patients diagnosed with brain tumors was 44. Among them, 11 were diagnosed with medulloblastoma, 1 with embryonic tumor PNS, 3 with ependynoma anaplastic, 4 with ependymoma, 2 with astrocytoma fibrous, 1 with astrocytoma, 1 with ganglioma, 8 with astrocytoma pilocytic, 1 with sub-ependymoma, 2 with hemangioblastoma, 4 with craniopharyngioma, 1 with dysembryoplastic neuroepithelial tumor, 1 with papillary glioneuronal tumor, 1 with testicular cancer metastasis, 1 with gliosarcoma, 1 with anaplastic oligodendroglioma and 1 sample with tumor metastasis. All patients were treated at the Polish Mother's Memorial Hospital Research Institute in Lodz. For breast cancers, the number of patients was 39, and all patients were diagnosed with infiltrating ductal carcinoma and treated at the M. Copernicus Voivodeship MultiSpecialist Center for Oncology and Traumatology in Lodz. None of the patients in this study have received chemotherapy and/or radiation therapy prior to surgery.

\subsection{Tissues Samples Collection and Preparation for Raman Spectroscopy}

Tissue samples were collected during routine surgery. The non-fixed samples were used to prepare 16 micrometers sections placed on $\mathrm{CaF}_{2}$ substrate (Crystran Ltd., Poole, UK; $\mathrm{CaF}_{2}$ Raman grade optically polished window $25 \mathrm{~mm}$ diameter $\times 1 \mathrm{~mm}$ thick, no.CAFP25$1 \mathrm{R}$, Poole, UK) for Raman analysis. In parallel, typical histopathological analysis by professional pathologists from the Polish Mother's Memorial Hospital Research Institute in Lodz for brain tissues samples or from Medical University of Lodz, Department of Pathology, Chair of Oncology, for breast tissues samples was performed. The types and grades of tumors according to the criteria of the current WHO Classification were diagnosed.

\subsection{Cell Culture and Preparation for Raman Spectroscopy}

The studies were performed on normal human astrocytes (Clonetics NHA), human astrocytoma CCF-STTG1 (ATTC CRL-1718) and human glioblastoma cell line U87-MG (ATCC HTB-14) purchased from Lonza (Lonza Walkersville. Inc., Walkersville, MA, USA) and 
American Type Culture Collection (ATCC), respectively. The NHA cells were maintained in Astrocyte Medium Bulletkit Clonetics (AGM BulletKit, Lonza CC-3186) and ReagentPack (Lonza CC-5034) without antibiotics in a humidified incubator at $37^{\circ} \mathrm{C}$ and $5 \% \mathrm{CO}_{2}$ atmosphere. The U87MG cells were maintained in Eagle's Minimal Essential Medium with L-glutamine (ATCC 30-2003) supplemented with 10\% fetal bovine serum (ATCC 30-2020) without antibiotics in a humidified incubator at $37^{\circ} \mathrm{C}$ and $5 \% \mathrm{CO}_{2}$ atmosphere. The CRL-1718 cells were maintained in RPMI1640 Medium (ATCC 30-2001) supplemented with $10 \%$ fetal bovine serum (ATCC 30-2020) without antibiotics in a humidified incubator at $37^{\circ} \mathrm{C}$ and $5 \% \mathrm{CO}_{2}$ atmosphere. A human desmoplastic cerebellar medulloblastoma cell line (ATCC HTB-186, Daoy) was grown in Eagle's Minimum Essential Medium (EMEM, ATCC 30-2003) supplemented with the fetal bovine serum to a final concentration of $10 \%$ (Gibco, Life Technologies, 16000-044). Cells were maintained without antibiotics at $37^{\circ} \mathrm{C}$ in a humidified atmosphere containing $5 \% \mathrm{CO}_{2}$. A human breast MCF10A cell line (CRL10317, ATCC) was grown with completed growth medium: MEGM Kit (Lonza CC3150) without gentamycin-amphotericin B mix (GA1000) and with $100 \mathrm{ng} / \mathrm{mL}$ cholera toxin, a slightly malignant human breast MCF7 cell line (HTB22, ATCC) in Eagle's Minimum Essential Medium (ATCC 30-2003) with 10\% fetal bovine serum (ATCC 30-2020) and a highly aggressive human breast MDA-MB-231 cell line (HTB26, ATCC) in Leibovitz's L15 Medium (ATCC 30-2008) with 10\% fetal bovine serum (ATCC 30-2020). All human breast cell lines were maintained at $37{ }^{\circ} \mathrm{C}$ in a humidified atmosphere containing $5 \% \mathrm{CO}_{2}$. Cells were seeded on $\mathrm{CaF}_{2}$ window (Crystran Ltd., Poole, $\mathrm{UK} ; \mathrm{CaF}_{2}$ Raman grade optically polished window $25 \mathrm{~mm}$ diameter $\times 1 \mathrm{~mm}$ thick, no.CAFP25-1R, Poole, UK) in a $35 \mathrm{~mm}$ Petri dish at a density of $5 \times 10^{4}$ cells per Petri dish the day before examination. Before Raman examination, cells were fixed with $4 \%$ formalin solution (neutrally buffered) and kept in phosphate-buffered saline (PBS, no. 10010023, Gibco) during the experiment.

\subsection{Raman Human Tissues Spectroscopic Measurements Ex Vivo}

A WITec (Ulm, Germany) alpha 300 RSA+ confocal microscope was used to record Raman spectra and imaging. The configuration of the experimental set-up was as follows: the diameter of fiber: $50 \mu \mathrm{m}$, a monochromator Acton-SP-2300i and a CCD camera Andor Newton DU970-UVB-353, the excitation laser line $532 \mathrm{~nm}$. The excitation line was focused on the sample through a $40 \times$ dry objective (Nikon, objective type CFI Plan Fluor C ELWD DIC-M, numerical aperture (NA) of 0.60 and a $3.6-2.8 \mathrm{~mm}$ working distance). The average laser excitation power was $10 \mathrm{~mW}$, with an integration time of $0.5 \mathrm{~s}$. Edge filters were used to remove the Rayleigh scattered light. A piezoelectric table was used to record Raman images. No pre-treatment of the samples was necessary before Raman measurements. The cosmic rays were removed from each Raman spectrum (model: filter size: 2, dynamic factor: 10) and the smoothing procedure, Savitzky-Golay method, was also implemented (model: order: 4, derivative: 0). Data acquisition and processing were performed using WITec Project Plus software.

\subsection{Statistical Analysis}

All results regarding the analysis of the intensity of the Raman spectra as a function of breast cancer or brain tumor grades are presented as the mean $\pm \mathrm{SD}$, where $p<0.05$ (SD—standard deviation, $p$ - probability value). Raman bands' intensity were taken and normalized by vector norm spectra. The Raman spectra were obtained from 39 (breast) and 44 (brain) patients. For each patient, thousands of spectra from different sites of the sample were obtained from cluster analysis. For breast, we typically used 8000 Raman spectra for averaging, and 6500 Raman spectra for brain tissue.

\subsection{Cluster Analysis}

Spectroscopic data were analyzed using the Cluster Analysis method. Briefly, Cluster Analysis is a form of exploratory data analysis in which observations are divided into different groups that have some common characteristics-vibrational features in our case. 
Cluster Analysis constructs groups (or classes or clusters) based on the principle that, within a group, the observations must be as similar as possible, while observations belonging to different groups must be different.

The partition of $\mathrm{n}$ observations $(x)$ into $k(k \leq n)$ clusters, $S$, should be carried out to minimize the variance (Var) according to the formula:

$$
\operatorname{argmin}_{S} \sum_{i=1}^{k} \sum_{x \in S i}\left\|x \mu_{i}\right\|^{2}=\operatorname{argmin}_{S} \sum_{i=1}^{k}\left|S_{i}\right| \operatorname{Var} S_{i}
$$

where $\mu_{i}$ is the mean of points $S_{i}$.

\section{Results}

\subsection{Cytochromes in Human Cancer Tissues}

To properly address redox state changes of mitochondrial cytochromes in brain and breast cancers by Raman spectroscopy and imaging, we systematically investigated how the Raman method responds to in vitro human cells and ex vivo human tissues [26,27]. In vitro experiments will allow to study a single cell by limiting the cell-to-cell interactions. The ex vivo human tissue experiments will extend our knowledge on the influence of environment on cancer development.

Recently, we compared the Raman spectra of the human breast and brain cancer tissues using different laser excitation wavelengths [27-29]. This approach might generate Raman resonance enhancement for some tissue components that cannot be visible for non-resonance conditions and provide selective spectral isolation of components crucial for understanding mechanisms of mitochondrial dysfunctions associated with cancers.

Figure 1 shows the spectrum of isolated cytochrome $c$ compared with the average Raman spectrum of ex vivo surgically resected specimens of human brain tissue at the G4 level and human breast tissue at the G3 level of malignancy at $532 \mathrm{~nm}$. The average Raman spectrum was obtained for 13 brain patients and 5 breast patients. For each patient diagnosed with brain cancer, 6500 Raman spectra were recorded, and for patients diagnosed with breast cancer, the number of single Raman spectra was 8000 .

The excitation at $532 \mathrm{~nm}$ enhances two types of components of the tissue: carotenoids (1520 and $\left.1156 \mathrm{~cm}^{-1}\right)$ and cytochromes $c$ and $b(750,1126,1310,1337,1363,1584,1248$, 1352 and $1632 \mathrm{~cm}^{-1}$ ) [30,31]. As the enhancement of carotenoids was discussed in our laboratory in many previous papers [13,32-36], here, we will concentrate on the cytochrome family. Using $532 \mathrm{~nm}$ laser excitation, one can monitor spectral features of complex III and cytochrome $c$ due to $Q$ bands at 500-550 $\mathrm{nm}$ related to intra-porphyrin transitions of the heme group in cytochrome $c[37,38]$.

Comparison of the Raman resonance spectra of the brain and breast tissues in Figure 1 with isolated cytochrome $c$ shows that most vibrations in the tissue correspond perfectly to vibrations of cytochrome c [30,31] upon $532 \mathrm{~nm}$ excitation. Correlation analysis shows a perfect match between the Raman peaks' positions of cytochrome $c$ in the human tissue and in pure cytochrome $c$ (Pearson correlation coefficient is 0.99951 at the confidence level 0.95 with the $p$-value of 0.0001$)$. In the Pearson correlation analysis, we took into account the Raman bands corresponding to cytochrome $c$ in the tissue and in pure cytochrome, so the presented Pearson correlation coefficient corresponds to the comparison to the maximum position of cytochrome bands.

One can see from Figure 1 that the vibrational mode at $1584 \mathrm{~cm}^{-1}$ appearing in the Q-resonant Raman spectrum at $532 \mathrm{~nm}$ is the most prominent band. The band at $1584 \mathrm{~cm}^{-1}$ appearing in the Q-resonant Raman spectra is characteristic of cytochrome $c$ [31]. Since Raman scattering is much weaker in the oxidized form of cytochrome $c$, the peak at $1584 \mathrm{~cm}^{-1}$ originates from the reduced form of cytochrome $c$ [39]. 

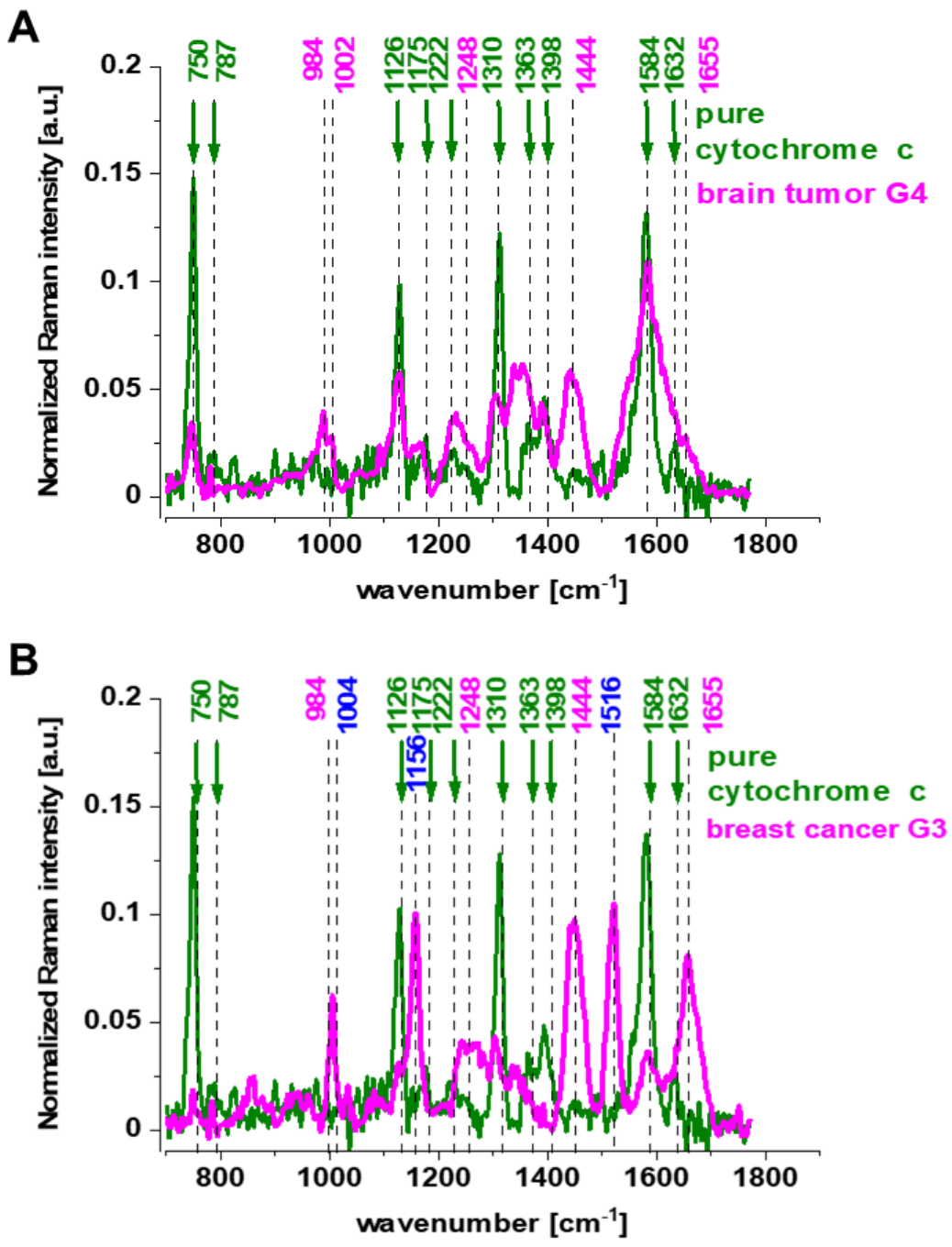

Figure 1. The average (number of patients $n(G 4)=13$, number of single Raman spectra 85,000) Raman spectra of the ex vivo human tissue of brain tumor, medulloblastoma (G4) - (pink), cytochrome $c$ (green) at the excitation at $532 \mathrm{~nm}(\mathbf{A})$, the average (number of patients $n(\mathrm{G} 3)=5$, number of single Raman spectra $n=40,000$ ) Raman spectrum of the ex vivo human tissue of breast cancer, infiltrating ductal carcinoma (IDC)) (G3) - (pink), cytochrome $c$ - (green) at the excitation at $532 \mathrm{~nm}$ (B).

Our results in Figure 1 demonstrate that the Raman intensity of $1584 \mathrm{~cm}^{-1}$ peak is the most sensitive vibration of redox status in the cell and is related to the concentration of the reduced cytochrome $c$. Therefore, we used $1584 \mathrm{~cm}^{-1}$ to study the redox state of mitochondrial cytochrome $c$ in brain and breast cells in vitro, and in ex vivo human tissues. The Raman spectra in Figure 1 do not provide information about the distribution of cytochrome $c$ in the cancer tissues. To learn about the distribution of cytochrome $c$, we used Raman imaging.

Figure 2 shows the Raman spectra and images for the human brain tissue of medulloblastoma (G4) and human breast tissue (infiltrating ductal carcinoma (IDC)) (G3). Creating Raman images by using specific filters for proteins, lipids and cytochrome $c$ or performing the Cluster Analysis as presented in Figure 2, one can analyze the distribution of proteins (red color), lipid profiles (blue color) and cytochrome (green color), and learn about the biochemical composition from the corresponding Raman spectra. 
A
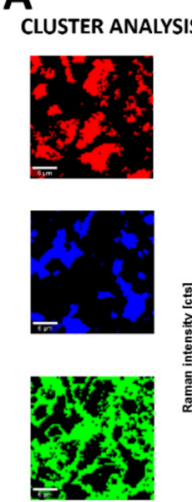

B

CLUSTER ANALYSIS
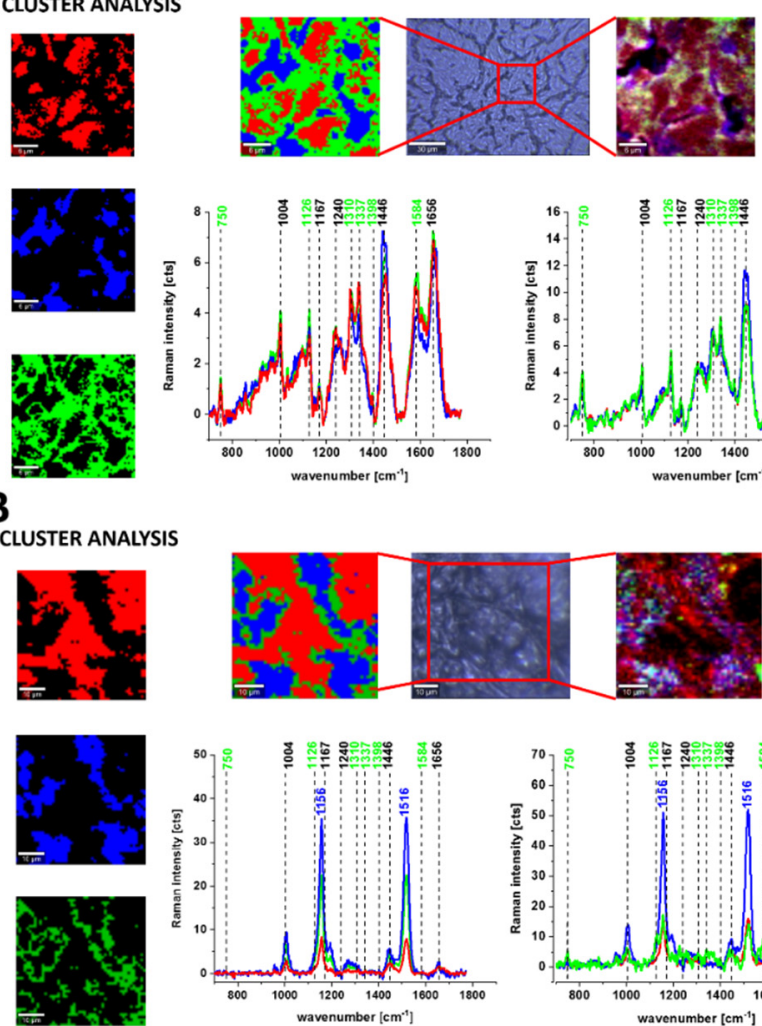

wavenumber [cm $\left.\mathrm{cm}^{-1}\right]$
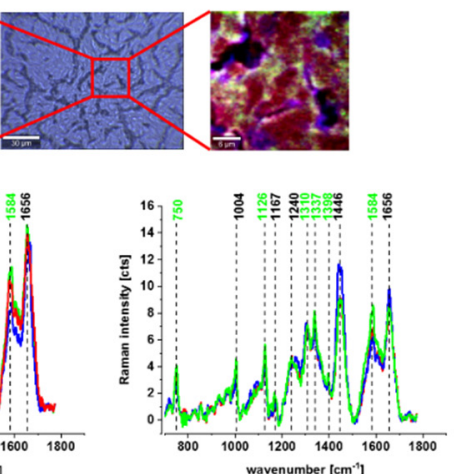

wavenumber [cm-1]

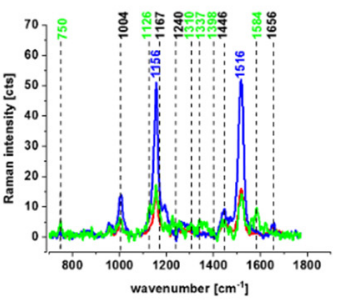

RAMAN FILTERS

1620-1700 [cm $\left.{ }^{-1}\right]$

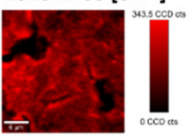

$1420-1460\left[\mathrm{~cm}^{-1}\right]$

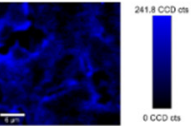

1560-1600 [cm $\left.{ }^{-1}\right]$

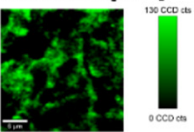

RAMAN FILTERS

$1620-1700\left[\mathrm{~cm}^{-1}\right]$

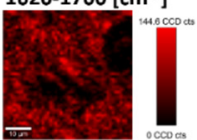

$1420-1460\left[\mathrm{~cm}^{-1}\right]$

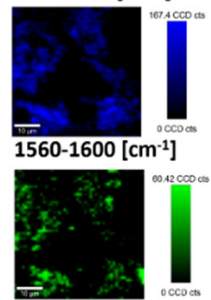

Figure 2. Microscopy image, Raman images of distribution of proteins (red color), lipids (blue color) and cytochrome $c$ (green) by using Cluster Analysis and Raman filters for brain tumor, grade IV medulloblastoma $(40 \times 40 \mu \mathrm{m}$, resolution $0.5 \mu \mathrm{m}$, integration time $1.0 \mathrm{~s}$, the average Raman spectra of lipids - blue, proteins - red, cytochrome - green at $532 \mathrm{~nm}$ ) (A). Microscopy image, Raman images of distribution of proteins (red color), lipids and carotenoids (blue color) and cytochrome $c$ (green) by using Cluster Analysis and Raman filters for breast cancer, grade III ductal cancer $(40 \times 40 \mu \mathrm{m}$, resolution $0.5 \mu \mathrm{m}$, integration time $1.0 \mathrm{~s}$, the average Raman spectra of lipids and carotenoids - blue, proteins - red, cytochrome - green at $532 \mathrm{~nm})($ B) .

Cytochrome Raman peaks observed for the spectra recorded at $532 \mathrm{~nm}$ excitation show resonance enhancement due to the electronic $Q$ band absorption for both $c$ - and $b$-type of cytochromes. It has been reported $[4,5,23,40]$ that the peaks at 750 and $1126 \mathrm{~cm}^{-1}$ are typical for both cytochrome $c$ and $b$, while the peaks at 1310 and $1398 \mathrm{~cm}^{-1}$ correspond to cytochrome $c$, and 1300 and $1337 \mathrm{~cm}^{-1}$ have been assigned to $b$-type cytochromes. It means that the peak at $1337 \mathrm{~cm}^{-1}$ can be used to track the reduced cytochrome $b$ form (ferrous $\left(\mathrm{Fe}^{2+}\right)$ cytochrome). Therefore, the peaks at 750 and $1126 \mathrm{~cm}^{-1}$ observed in Raman spectra of human brain and breast tissues presented in Figure 3 will be used to evaluate contributions of cytochrome $b$ and cytochrome $c$.

To track the amount of the ferrous cytochrome $c$ in brain and breast cancer tissues, we have analyzed the intensity of the band at $1584 \mathrm{~cm}^{-1}$ assigned to the vibrational mode $v_{19}$. In this spectral region, there are several overlapping Raman bands $\left(v_{19}\right.$ of ferric heme $c\left(1582 \mathrm{~cm}^{-1}\right), v_{19}$ of ferrous heme $c\left(1582 \mathrm{~cm}^{-1}\right), v_{2}$ of ferric heme $c\left(1585 \mathrm{~cm}^{-1}\right)$, $v_{19}$ of ferrous heme cyt $b\left(1586 \mathrm{~cm}^{-1}\right)$ and $v_{2}$ of ferrous heme $\left.b\left(1583 \mathrm{~cm}^{-1}\right)\right)$. Fortunately, all vibrational modes of ferric cytochrome can be eliminated from the further discussion due to the fact that the intensities of these peaks are very weak compared to the signals of ferrous forms, with one exception of the band at $1634 \mathrm{~cm}^{-1}$. Thus, the bands at $1584 \mathrm{~cm}^{-1}$ (reduced cyt $c$ ) and at $1634 \mathrm{~cm}^{-1}$ (oxidized cyt $c$ ) of cytochrome $c$ can be used as a very important parameter controlling the level of reduction in cancer tissues and cells. 
A

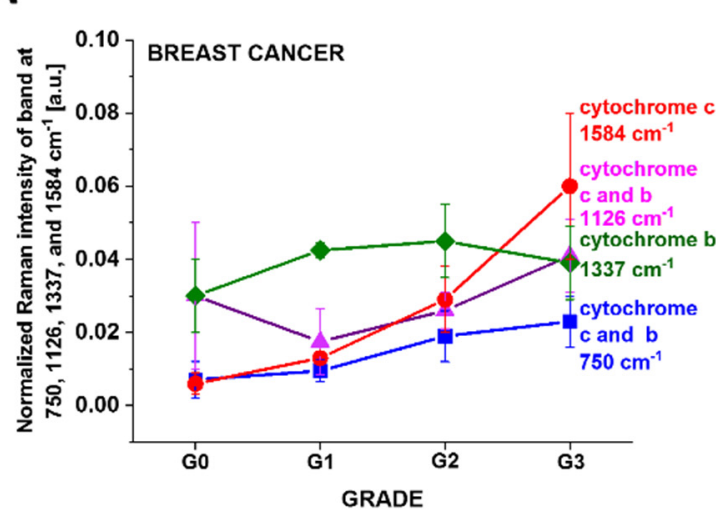

B

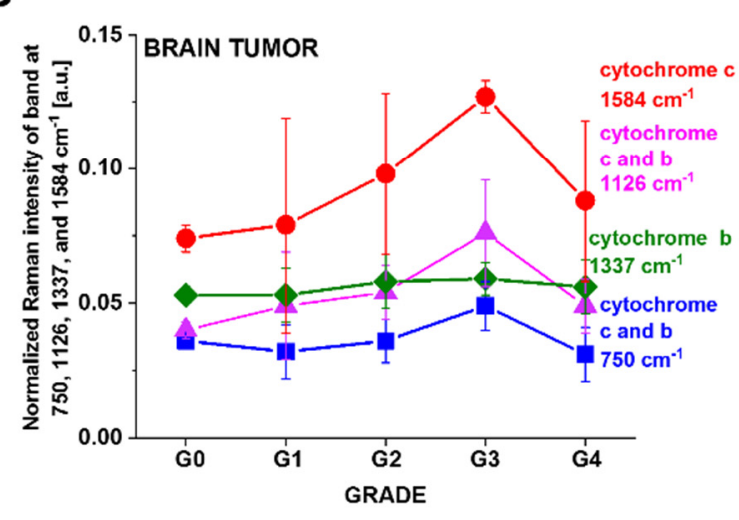

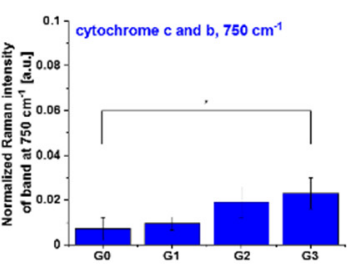
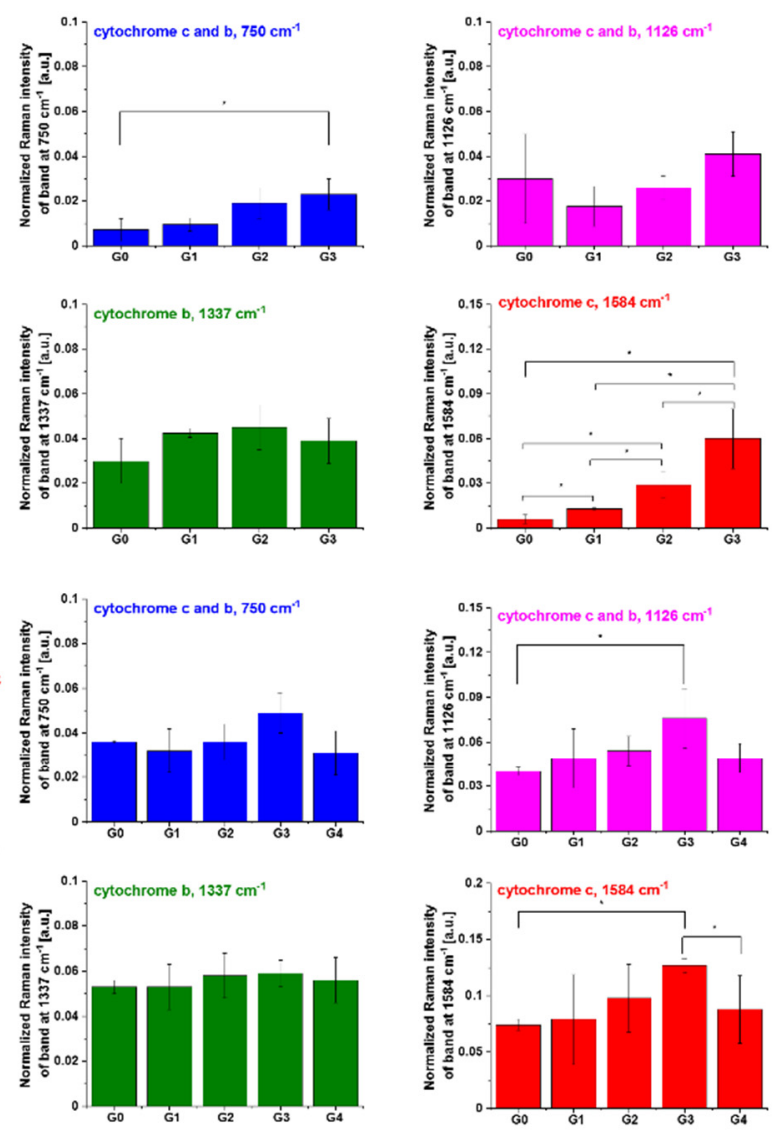

Figure 3. Raman intensity of the 750,1126, 1337 and $1584 \mathrm{~cm}^{-1}$ peaks as a function of grade for breast normal (G0) and cancer (invasive ductal cancer) human tissue (G1, G2, G3) (average \pm SD from number of patients $n=39$, number of single Raman spectra $=305,000)(A)$. Raman intensity of the 750,1126, 1337 and $1584 \mathrm{~cm}^{-1}$ peaks as a function of grade for brain normal (G0) and tumor tissues (G1, G2, G3, G4) (average \pm SD from number of patients $n=44$, number of single Raman spectra $=280,000)(B)$. The statistically significant results have been marked with an asterix.

In view of the results presented so far, we can state that Raman spectroscopy can be used in probing biochemical concentrations of cytochromes in normal and cancer cells.

To check whether cytochromes are upregulated in brain and breast cancers, we studied the Raman signals corresponding to cytochromes as a function of cancer malignancy using grades. The grade is evaluated on the basis of how much the cancer cells look like normal cells and measure cell anaplasia (reversion of differentiation). The malignancy for breast cancer is expressed on a three-point scale, G1-G3, while for brain human tumors, on a four-point scale, G1-G4 [40].

Figure 3A shows the intensity of the 750, 1126, 1337 and $1584 \mathrm{~cm}^{-1}$ Raman vibrations as a function of grade for breast normal (G0) and cancer (invasive ductal cancer) human tissue (G1, G2, G3). We calculated the average Raman spectra for each Raman vibration. The total number of patients $(n)$ is 39 , and for each patient, thousands of spectra obtained from Raman imaging were used for averaging. Based on the average values obtained for the Raman biomarkers of cytochrome $c$ and $b$, we obtained a plot as a function of breast grade malignancy, and the statistically significant results have been marked with an asterix.

One can see from Figure 3A that the intensity of the Raman biomarker at $1584 \mathrm{~cm}^{-1}$ corresponding to concentration of cytochrome $c$ increases with breast cancer aggressiveness. The intensity of the Raman biomarker at $1337 \mathrm{~cm}^{-1}$ corresponding to concentration of cytochrome $b$ does not change with breast cancer aggressiveness. The intensities of Raman biomarkers at 750 and $1126 \mathrm{~cm}^{-1}$ corresponding to concentration of cytochromes $c$ and $b$ increase with breast cancer aggressiveness. 
Figure $3 \mathrm{~B}$ shows that for brain tissues, the Raman intensities of the characteristic vibrations of cytochrome $c\left(1584 \mathrm{~cm}^{-1}\right)$ and cytochromes $c$ and $b\left(750\right.$ and $\left.1126 \mathrm{~cm}^{-1}\right)$ first increase with increasing of cancer aggressiveness up to G3, and then decreases for G4.

The Raman intensity of the band at $1337 \mathrm{~cm}^{-1}$ corresponding to the concentration of the reduced cytochrome $b$ does not change vs. tumor brain aggressiveness when compared with the normal tissue.

In the view of the results presented in Figure 3, it is evident that the Raman biomarker $\mathrm{I}_{1584}$ measuring contribution of cytochrome $c$ in the human tissues correlates with cancer aggressiveness. The intensity of the $1584 \mathrm{~cm}^{-1}$ Raman signal corresponding to concentration of reduced cytochrome $c$ increases with increasing cancer aggressiveness. It indicates that cytochrome $c$ plays a crucial role in the development and progression of cancer. The dependence of the Raman biomarker $\mathrm{I}_{1584}$ of the reduced cytochrome $c$ in Figure 3 vs. cancer malignancy shows that the optimal concentration of cytochrome $c$ in the tissue that is needed to maintain cellular homeostasis corresponds to the Raman normalized intensity of $0.006 \pm 0.003$ for the breast tissue and $0.074 \pm 0.005$ for brain tissue. The concentrations of the reduced cytochrome $c$ at this level modulate protective, signaling-response pathways, resulting in positive effects on life-history traits. The reduced cytochrome $c$ level above the value corresponding to G0 triggers a toxic runaway process and aggressive cancer development. The plot in Figure 3 provides an important cell-physiologic response. Normally, concentration of the reduced cytochrome $c$ operates at a low, basal level in normal cells, but it dramatically increases to very high levels in pathological cancer states.

\subsection{Cytochromes in Cancer Human Single Cells}

To understand this cell-physiologic response of cytochrome $c$ due to cancer aggressiveness, we used model systems of culturing lines of breast and brain cancer cells. It has become well-known that the model systems of culturing cancer cells may not perfectly reproduce the biochemistry or physiology of human cancers and tumors in tissues [41]. However, they can provide information about the role of cytochrome $c$ in single isolated cells by limiting cell-cell interactions and the effect originating from the extracellular matrix existing in the tissue.

We studied normal in vitro breast cells (MCF10A) (G0), slightly malignant MCF7 cells (G2) and highly aggressive MDA-MB-231 cells (G3) and human brain cells of normal astrocytes (NHA) (G0), astrocytoma (CRL-1718) (G2), glioblastoma (U-87 MG) (G4) and medulloblastoma (Daoy) (G4). We wanted to check if the main cytochrome $c$ Raman biomarkers are also upregulated in cancers and increase with cancer aggressiveness.

To learn about cytochrome $c$ in mitochondria or in cytoplasm by methods of conventional molecular biology, one would have to disrupt a cell to break it open and release the cellular structure to recover fractions that are enriched with mitochondria. Using Raman imaging, we do not need to disrupt cells to learn about localization, distribution and biochemical composition of cytochromes in different organelles.

Figure $4 \mathrm{~A}$ shows the Raman image of a single cell MDA-MB-231 and U-87 MG of highly aggressive breast and brain cancer and corresponding Raman spectra. Creating Raman images by K-means Cluster Analysis, one can analyze the distribution of proteins, lipids and cytochromes in different organelles of the cell and learn about the biochemical composition from the corresponding Raman spectra. The red color represents nucleus, orange color represents lipid droplets, green-mitochondria, blue-cytoplasm and grey-membrane.

The peaks at 750, 1126 and $\sim 1584 \mathrm{~cm}^{-1}$ are associated with cytochrome $c$, while the peak at $1337 \mathrm{~cm}^{-1}$ is associated with cytochrome $b$. Comparing the Raman intensities in different organelles of single cells, one can see from Figure 4 that the highest concentration of cytochrome $c\left(1584 \mathrm{~cm}^{-1}, 750 \mathrm{~cm}^{-1}\right)$ is observed in mitochondria. We can also observe the release of cytochrome $c$ into the cytoplasm. 
Breast cell line MDA-MB-231

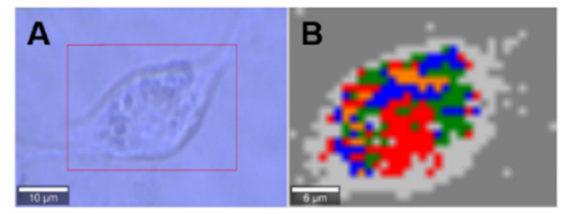

C

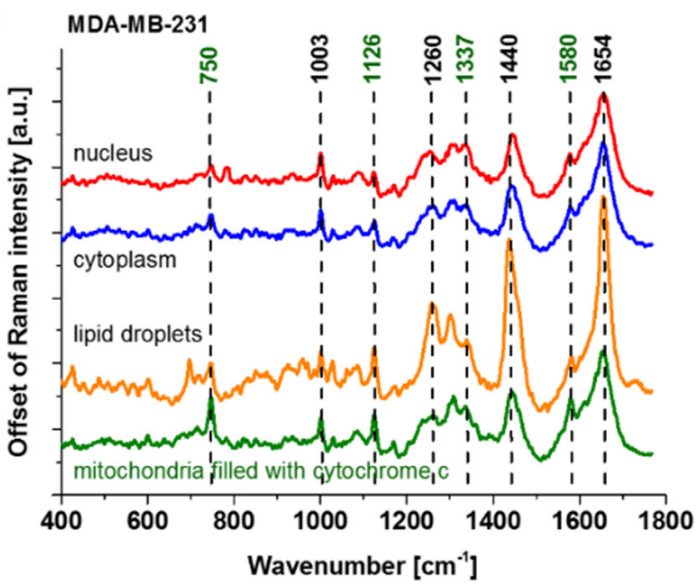

Brain cell line U-87 MG

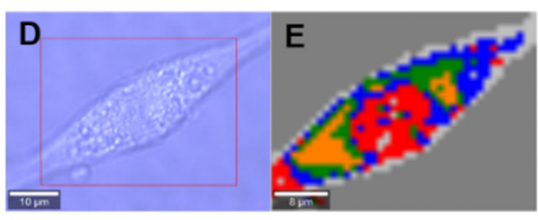

$\mathbf{F}$

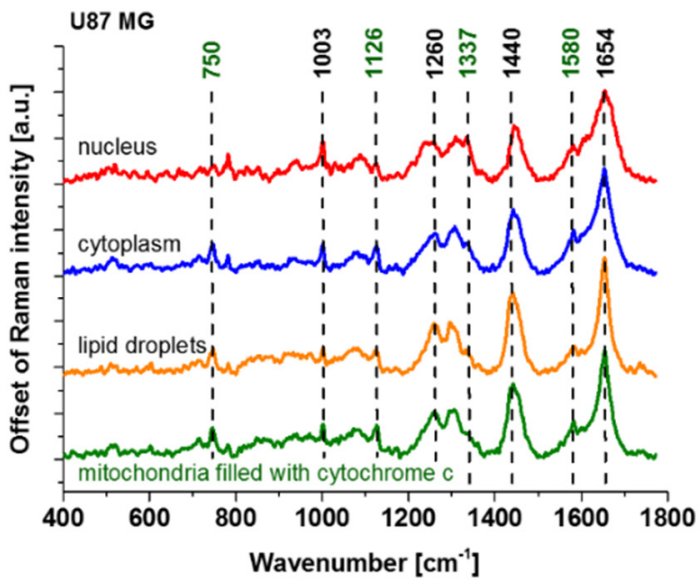

Figure 4. Microscopy image (A), Raman image (35 $\times 26 \mu \mathrm{m}$, resolution $0.5 \mu \mathrm{m}$, integration time $1.0 \mathrm{~s})(\mathbf{B})$, the average Raman spectra (number of cells $n=3$, number of single Raman spectra $n=10,920$ ) of nuclei (red), cytoplasm (blue), lipid droplets (orange), mitochondria (green) (C), at $532 \mathrm{~nm}$ of single cell MDA-MB-231. Microscopy image (D), Raman image $(40 \times 30 \mu \mathrm{m}$, resolution $0.5 \mu \mathrm{m}$, integration time $1.0 \mathrm{~s})(\mathbf{E})$, the average Raman spectra (number of cells $n=3$, number of single Raman spectra $n=14,400$ ) of nuclei (red), cytoplasm (blue), lipid droplets (orange), mitochondria (green) (F), at $532 \mathrm{~nm}$ of single cell U-87 MG.

The significance of mitochondrial dysfunctionality has not been studied by the Raman method in invasive ductal carcinoma (IDC) to the best of our knowledge, but the other conventional biological methods have been used to study this subject [19]. The results on the role of cytochrome $c$ in brain disorders of different groups are somewhat conflicted regarding the respiratory chain in glioma $[15,16]$.

Let us concentrate on cytochrome $c$ concentration in mitochondria as a function of cancer aggressiveness in breast and brain cells.

Figure 5 shows the Raman intensities $\mathrm{I}_{750}, \mathrm{I}_{1126}, \mathrm{I}_{1337}$ and $\mathrm{I}_{1584} \mathrm{~cm}^{-1}$ of vibrational peaks as a function of breast and brain cells' aggressiveness, where the statistically significant results have been marked with an asterix.

One can see from Figure 5 that the intensity of the Raman biomarker at $1584 \mathrm{~cm}^{-1}$ corresponding to concentration of cytochrome $c$ in mitochondria of a single cell increases with breast cancer aggressiveness and decreases with brain tumor aggressiveness. The intensity of the Raman biomarker at $1337 \mathrm{~cm}^{-1}$ corresponding to concentration of cytochrome $b$ does not change with breast cancer and decreases with brain tumor aggressiveness. The intensities of Raman biomarkers at 750 and $1126 \mathrm{~cm}^{-1}$ corresponding to concentrations of cytochromes $c$ and $b$ increase with breast cancer aggressiveness. For brain tumors, the intensity of the Raman biomarker at $750 \mathrm{~cm}^{-1}$ does not change with tumor aggressiveness, and for $1126 \mathrm{~cm}^{-1}$, it increases for tumor cells compared to normal cells.

Figure 6 shows the comparison of Raman peak intensities $I_{1584}, I_{1126}, I_{1337}$ and $\mathrm{I}_{750} \mathrm{~cm}^{-1}$ corresponding to cytochromes for human breast tissues and cells.

One can see from Figure 6 that both breast cancer tissues and breast cancer cell lines in vitro show similar trends. The higher concentration of the reduced cytochrome $c$ in mitochondria of cancer cells (MCF7 (G2) and MDA-MB-231 (G3)) in vitro when compared with the normal cells (MCF10A (G0)) as presented in Figure 6 indicates that the reduced form of cytochrome $c$ is upregulated in breast cancer cells. 
A

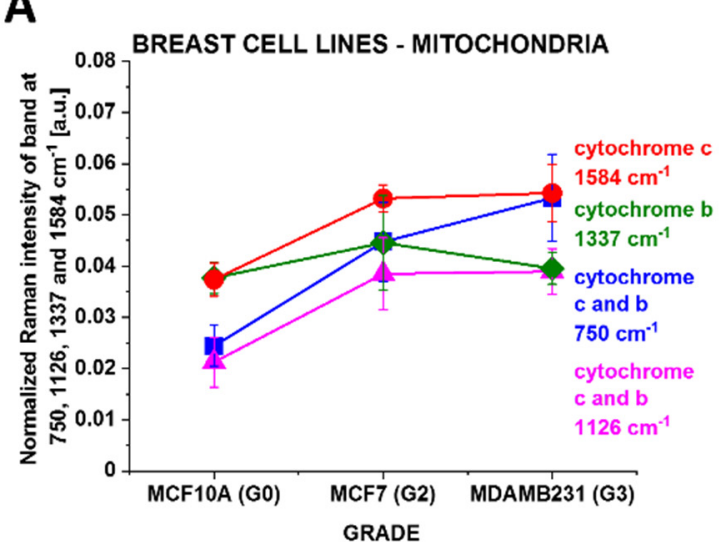

\section{B}

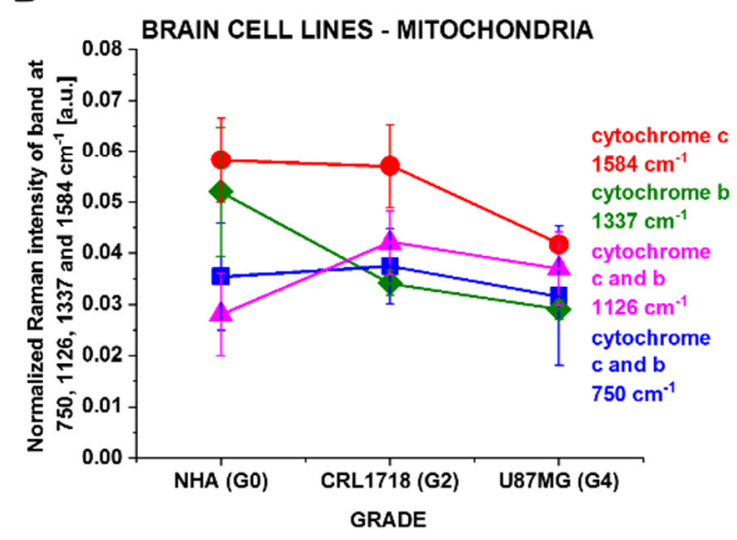

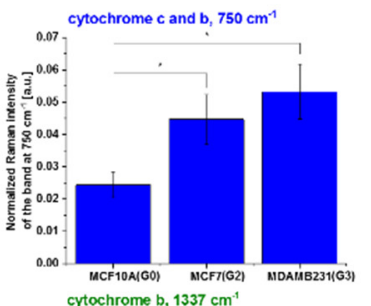
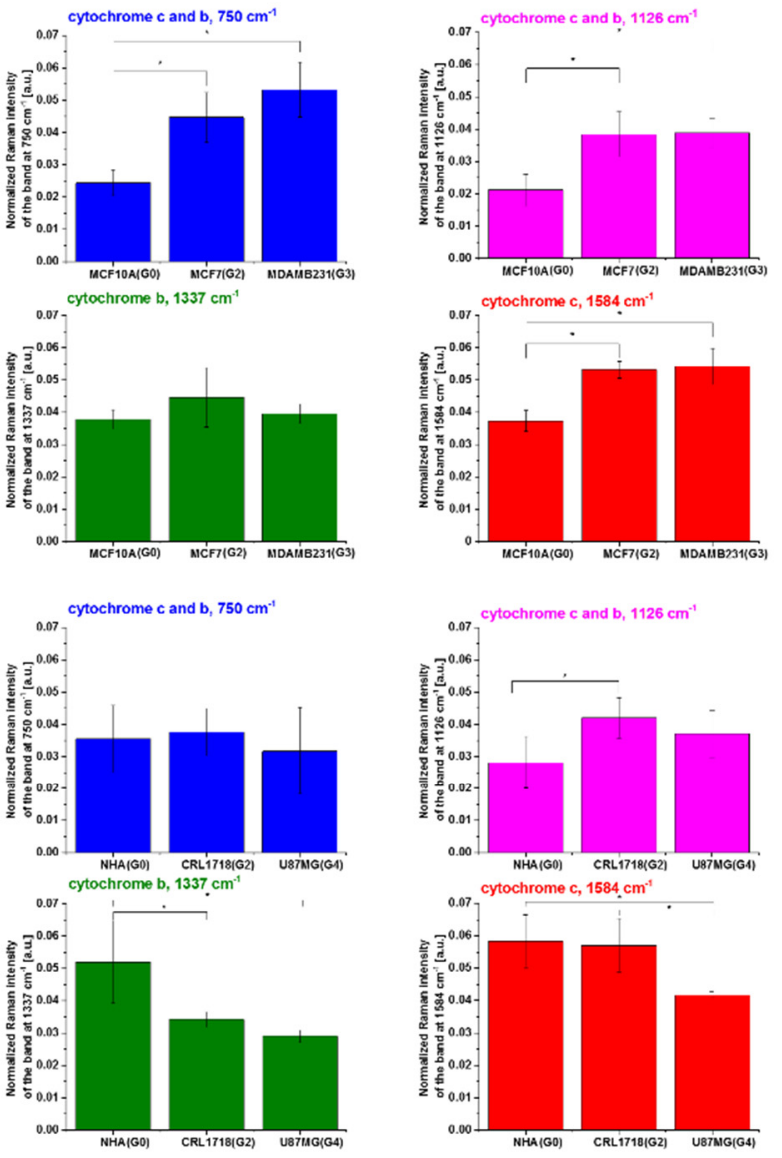

Figure 5. The Raman intensities of cytochrome $c$ and cytochrome $b$ in mitochondria of single cells in vitro culturing for (A) human breast and (B) brain: $\mathrm{I}_{750}, \mathrm{I}_{1126}, \mathrm{I}_{1337}$ and $\mathrm{I}_{1584} \mathrm{~cm}^{-1}$ as a function of breast cancer grade malignancy G0-G3 and brain tumor grade malignancy G0-G4 at excitation $532 \mathrm{~nm}$. The statistically significant results have been marked with an asterix.

A

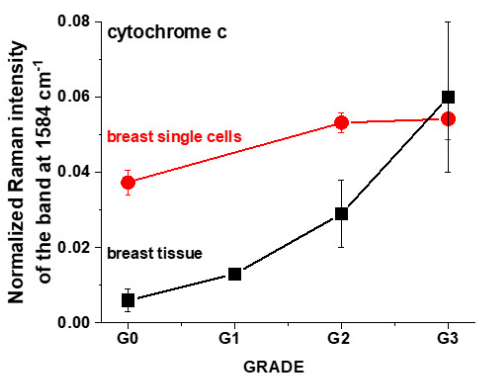

C

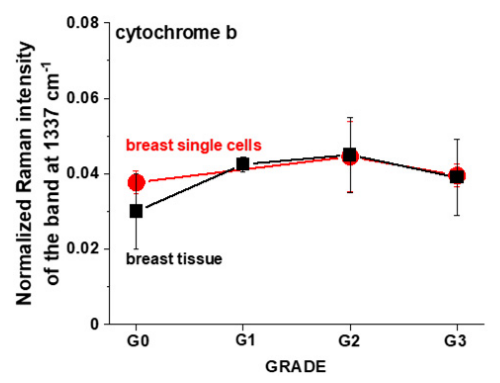

B

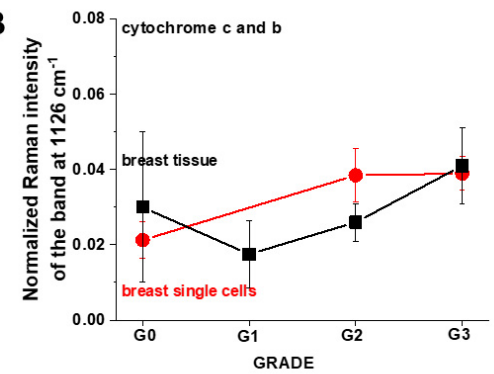

D

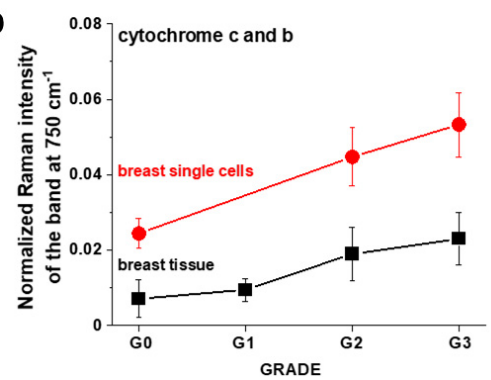

Figure 6. Raman intensities of cytochrome $c$ and cytochrome $b$ in mitochondria of single in vitro breast cells and tissues: (A) $\mathrm{I}_{1584}$, (B) $\mathrm{I}_{1126}$, (C) $\mathrm{I}_{1337}$ and (D) $\mathrm{I}_{750} \mathrm{~cm}^{-1}$ as a function of breast cancer grade malignancy $\mathrm{G} 0-\mathrm{G} 3$ at excitation $532 \mathrm{~nm}$. 
Figure 7 shows the Raman intensities $\mathrm{I}_{1584}, \mathrm{I}_{1126}, \mathrm{I}_{1337}$ and $\mathrm{I}_{750} \mathrm{~cm}^{-1}$ of vibrational peaks as a function of brain aggressiveness.
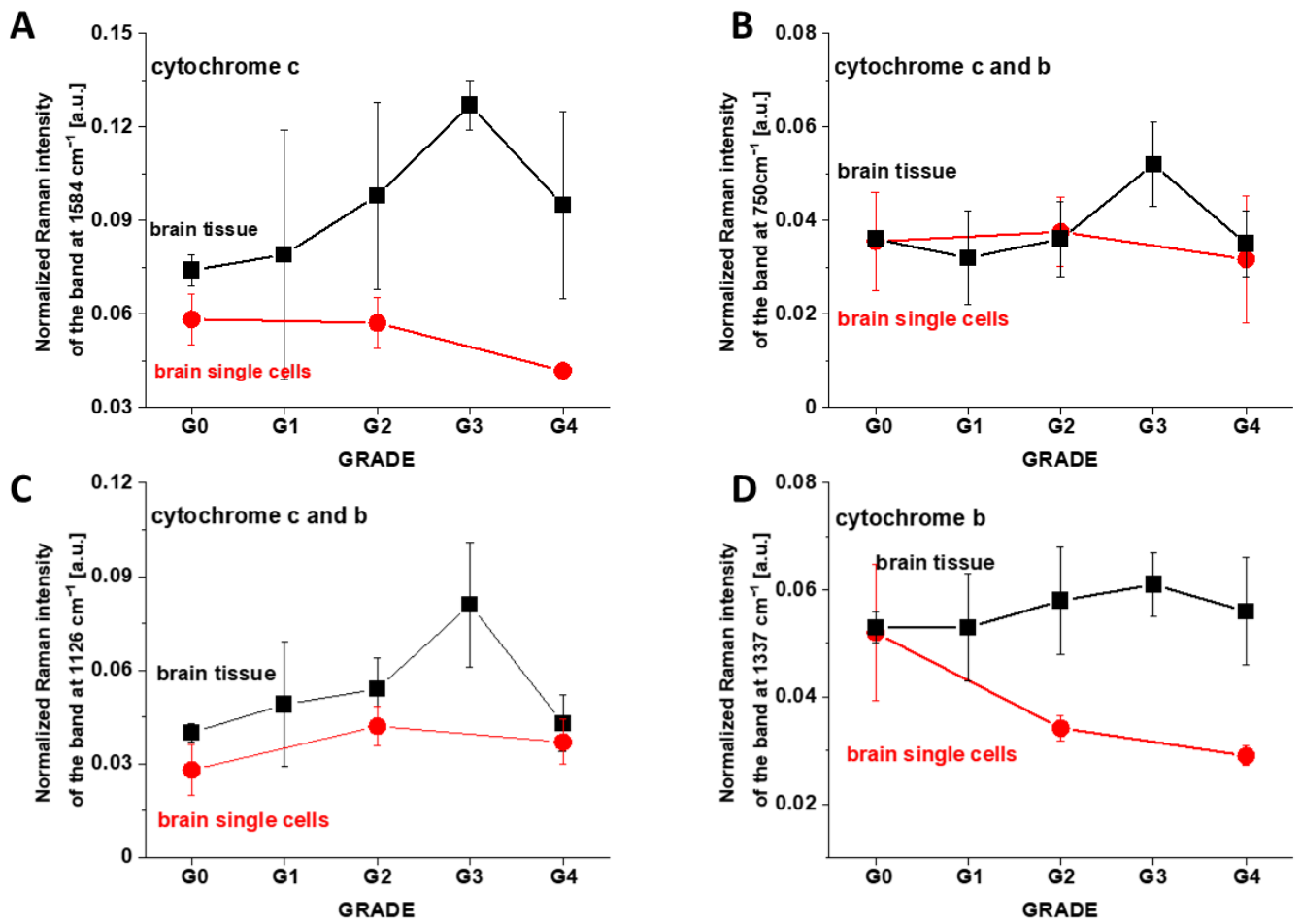

Figure 7. Raman intensities of cytochrome $c$ and cytochrome $b$ in mitochondria of single in vitro cells and in the brain tissue: (A) $\mathrm{I}_{1584},\left(\right.$ B) $\mathrm{I}_{1126},\left(\right.$ C) $\mathrm{I}_{1337}$ and (D) $\mathrm{I}_{750}$ as a function of brain tumor grade malignancy G0-G4 at excitation $532 \mathrm{~nm}$.

One can see from Figure 7 that the intensity of the Raman biomarker at $1584 \mathrm{~cm}^{-1}$ corresponding to concentration of cytochrome $c$ in mitochondria of a single cell decreases with brain tumor aggressiveness. The intensity of the Raman biomarker at $1337 \mathrm{~cm}^{-1}$ corresponding to concentration of cytochrome $b$ also decreases with brain tumor aggressiveness. Figure 7 demonstrates that brain tumor tissue and brain tumor single cells in vitro show opposite trends. The lower concentration of the reduced cytochrome $c$ in mitochondria of tumor cells in vitro when compared with the normal cells as presented in Figure 7 indicates that the reduced form of cytochrome $c$ is downregulated in brain tumor cells.

In normal cells, cytochrome $c$ is found in the mitochondria. The release of cytochrome $c$ into the cytoplasm induces the non-inflammatory process of apoptosis. When it is transferred to the extracellular space, it can cause inflammation. The assessment of cytochrome $c$ in the extracellular space might be used as a biomarker for determining mitochondrial damage and cell death.

We studied the concentration of cytochrome $c$ and $b$ using Raman markers $\mathrm{I}_{750}, \mathrm{I}_{1126}$, $\mathrm{I}_{1337}$ and $\mathrm{I}_{1584}$ in cytoplasm as a function of cancer aggressiveness. Figure 8 shows normalized Raman intensities of cytochrome $c$ and cytochrome $b$ in cytoplasm of single in vitro cells: $\mathrm{I}_{750}, \mathrm{I}_{1126}, \mathrm{I}_{1337}$ and $\mathrm{I}_{1584}$, as a function of breast cancer and brain tumor malignancy at excitation of $532 \mathrm{~nm}$.

One can see from Figure 8A,B that in the breast and brain single cells in vitro, the concentration of cytochrome $c$ found in the cytoplasm does not increase with cancer aggressiveness, because the results in Figure 8 are not the statistically significant. 
A

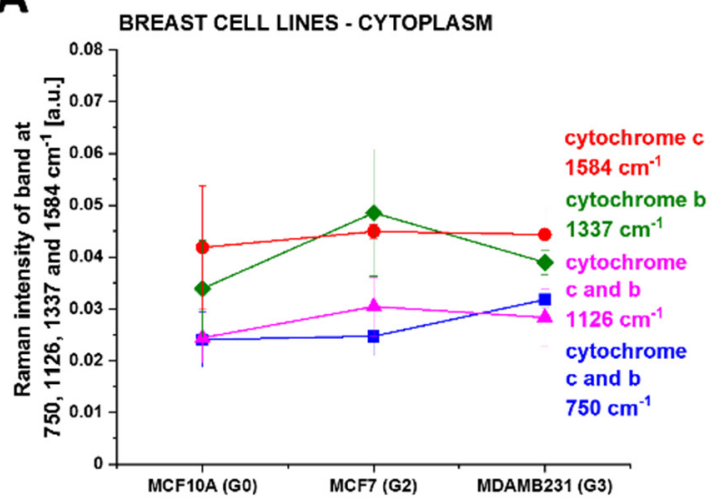

B

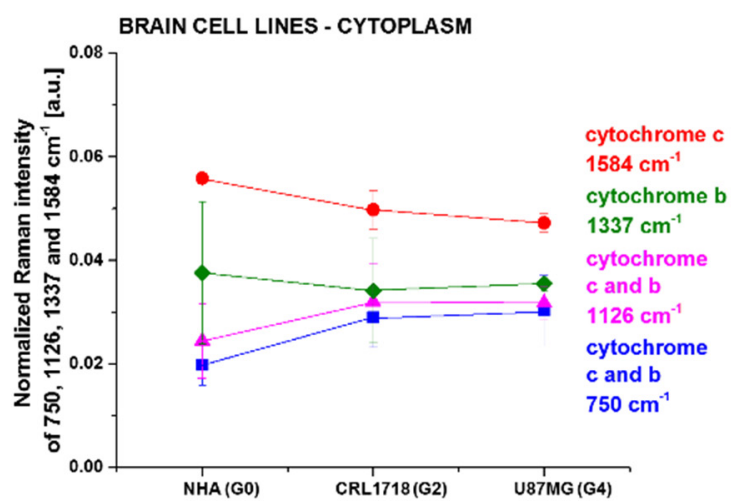

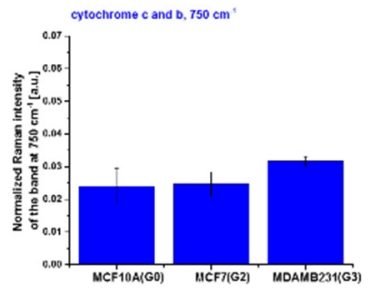
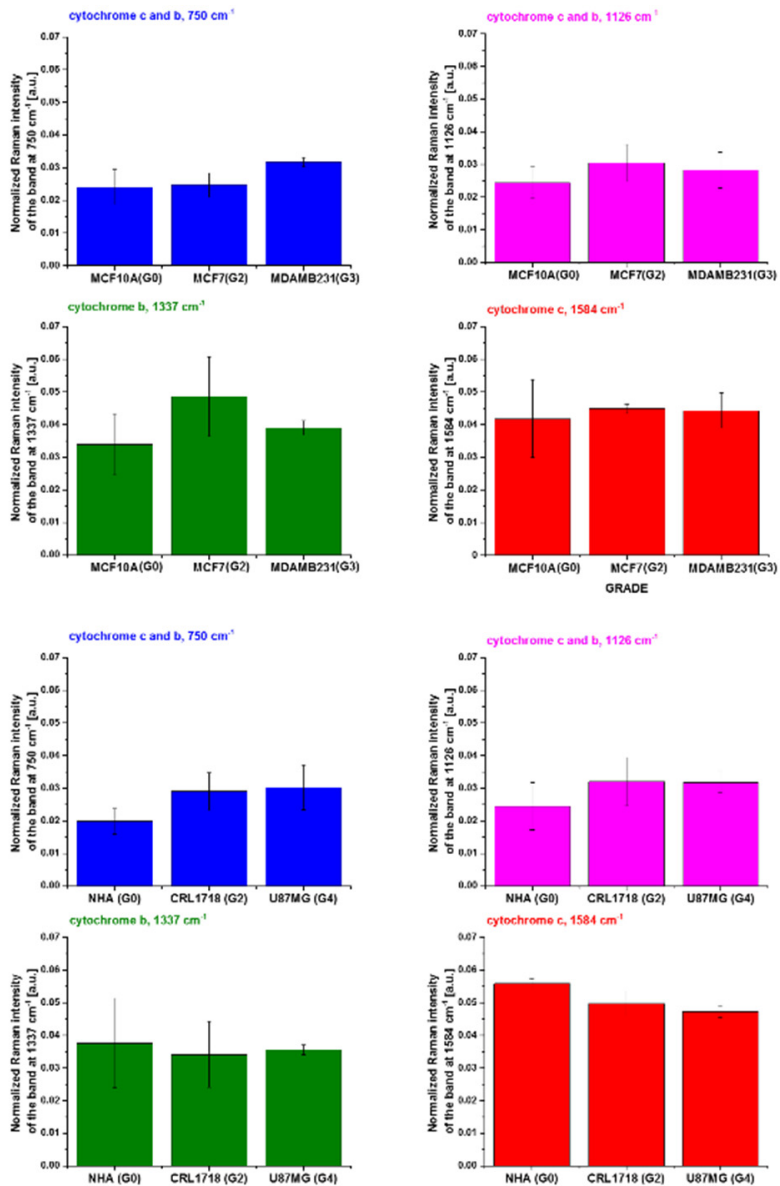

Figure 8. Normalized Raman intensities of cytochrome $c$ and cytochrome $b$ in cytoplasm of single in vitro cells: $\mathrm{I}_{750}, \mathrm{I}_{1126}$, $\mathrm{I}_{1337}$ and $\mathrm{I}_{1584}$ as a function of breast cancer (A) and brain tumor malignancy (B) at excitation of $532 \mathrm{~nm}$.

\section{Discussion}

\subsection{Discrepancies between Tissues and In Vitro Cells vs. Cancer Aggressiveness}

In view of the results presented so far, we showed that breast cancer tissue and breast cancer cell lines in vitro show similar trends. The concentration of cytochrome $c$ increases with increasing breast cancer aggressiveness. In contrast, the results demonstrate that brain tumor tissue and brain tumor single cells in vitro show opposite trends. The concentration of cytochrome $c$ increases with increasing brain tumor aggressiveness in the tissue, while the concentration of cytochrome $c$ decreases with increasing breast cancer aggressiveness in single cells in vitro. Here, we will discuss the possible reason of these discrepancies between tissues and in vitro cells vs. cancer aggressiveness to explain why this relationship is reversed.

First, in single cells, we analyze concentration of cytochromes in separate organelles, such as mitochondria in Figures 5 and 8. In the tissue, we measure the global concentration of cytochrome $c$, not only inside the cell, but also outside in the extracellular matrix due to the release of cytochrome from cells. Second, interactions between epithelial cells and extracellular matrix in the tissue results in induction of various mechanisms such as caspase-dependent cytochrome $c$ release that may occur by distinct mechanisms than in single cells in vitro.

To clarify this point, let us focus on the role of cytochrome $c$ in mechanisms that regulate mitochondrial dysfunction in cancers. Our results for single cells presented above provide a first hint on the role of cytochrome $c$ in mechanisms that regulate cancer progression by using redox-sensitive mitochondrial cytochrome Raman bands for label-free detection of mitochondrial dysfunction. 
To understand the role of cytochrome $c$, we summarize the most important events with its involvement in oxidative phosphorylation (OXPHOS). Briefly, as shown in Scheme 1A, a series of coordinated enzymatic reactions are involved in the flow of carbons from glucose to fatty acids. First, glucose derived from dietary carbohydrates undergoes glycolysis, and pyruvate generated from glycolysis is changed into the compound known as acetylCoA. Many intermediate compounds are formed in the TCA cycle which are used in synthesis of other biomolecules, such as amino acids, nucleotides, chlorophyll, cytochromes and fats. The third part of cellular respiration in mitochondria is oxidative phosphorylation, which is essential to the maintenance of life. The OXPHOS process oxidizes glucose derivatives, fatty acids and amino acids to carbon dioxide $\left(\mathrm{CO}_{2}\right)$ through a series of enzymecontrolled steps. In this part, OXPHOS starts with the respiratory electron transport chain (Scheme 1B), transferring electrons originating from NADH and succinate through four protein complexes (complex I IV) with the help of ubiquinone and cytochrome $c$. During the electron transfer process, a proton gradient is generated across the inner mitochondrial membrane, which in turn drives ATP synthase to synthesize ATP [42].

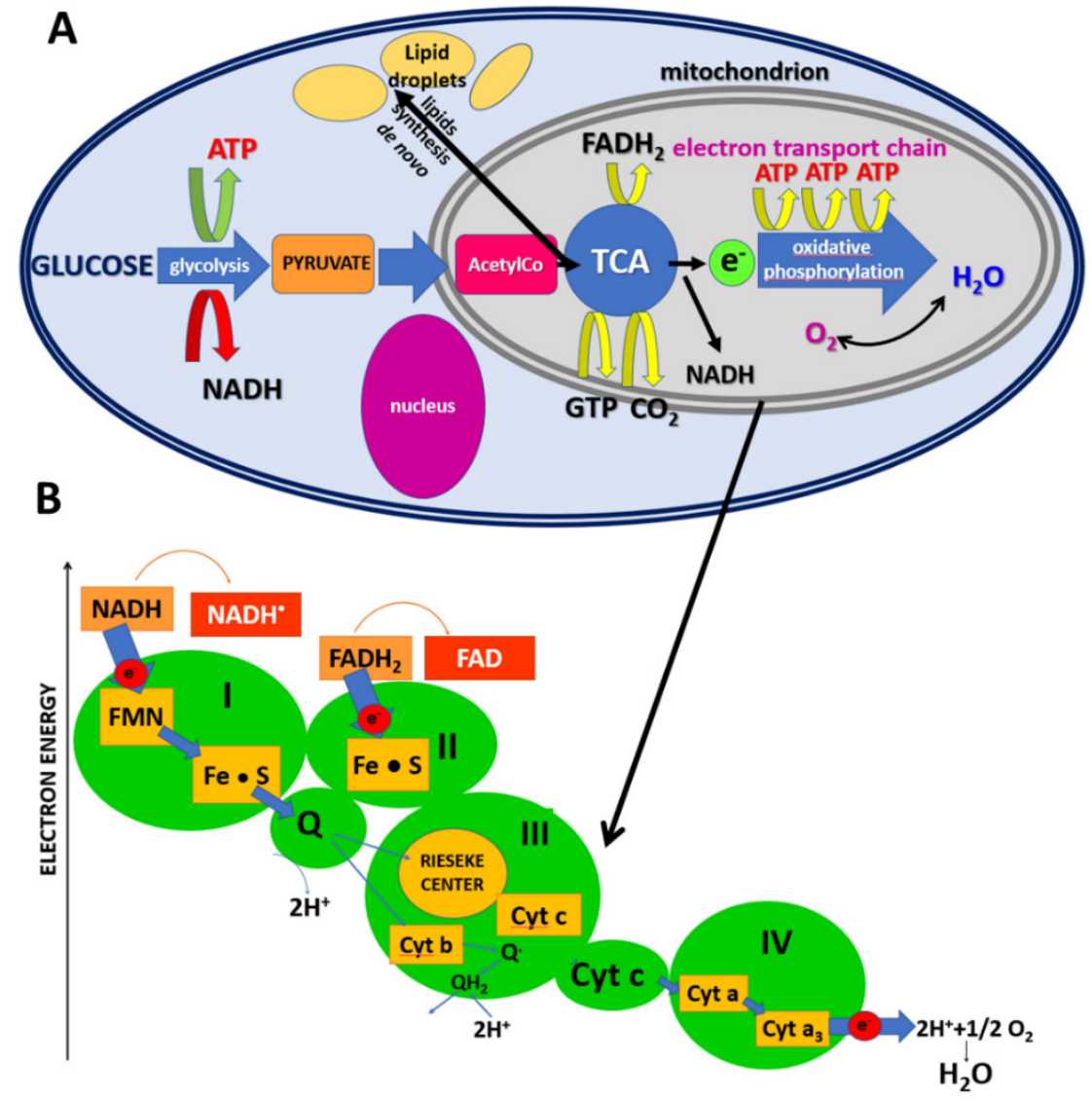

Scheme 1. Glycolysis takes place in the cytoplasm. Within the mitochondrion, the citric acid cycle (TCA) occurs in the mitochondrial matrix (A), and oxidative metabolism and the electron transport chain occur at the internal mitochondrial membranes (B).

Scheme 1B shows the electron transport chain with involvement of cytochrome $c$. Briefly, the electrons are transported in a series of events via electron transporters embedded in the inner mitochondrial membrane that shuttles electrons from NADH and $\mathrm{FADH}_{2}$ to molecular oxygen. As a result of these processes, protons are pumped from the mitochondrial matrix to the intermembrane space, and oxygen is reduced to form water. The cytochrome $c$ is localized in the inner membrane of mitochondrium and transfers electrons between complex III and complex IV of the respiratory chain (Scheme 1), generating the proton gradient and triggering ATP production. The heme chromophore of 
cytochrome $c$ accepts electrons from the $b c_{1}$ complex (complex III) and transfers electrons to the complex IV. Under normal physiological conditions, when the electron transport chain and chemiosmosis make up oxidative phosphorylation, there is a balance between the oxidized and reduced forms of cytochrome $c$, which depends on the efficiency of the electron transport from complex I to complex IV.

Our results presented so far demonstrate that the mechanisms controlling the electron transport chain might be deregulated in cancers and the level of dysfunction measured as concentration of reduced cytochrome $c$ increases with tumor aggressiveness. At normal physiological conditions, the oxidized form of the cytochrome $c$ heme group can accept an electron from the heme group of the cytochrome $c_{1}$ subunit of cytochrome reductase (complex III). Cytochrome $c$ then transfers this electron to the cytochrome oxidase complex (complex IV).

Our results in Figure 7 demonstrate that concentration of reduced cytochrome $c$ in mitochondria of brain single cells monitored by the Raman signal at $1584 \mathrm{~cm}^{-1}$ decreases with increasing malignancy level. It indicates that complex III shows reduced activity in transferring electrons to cytochrome $c$ with increasing malignancy level. Additionally, concentration of cytochrome $b$ also decreases with tumor malignancy (Figure 7D). The results from Figure 7D suggest that cancer cells are deficient in subunit cytochrome $b$ in the complex III, which are unable to maintain respiratory function. Thus, the results from Figure 7 demonstrate that electron transport, organized in terms of electronegativity, is inhibited between complex III and complex IV (Scheme 1).

The results for brain support earlier suggestions that the $Q_{o}$ site of the mitochondrial complex III is required for the transduction of hypoxic signaling via reactive oxygen species production [43]. Cancer cells deficient in subunit cytochrome $b$ in the complex III, which are unable to maintain respiratory function, increase ROS levels and stabilize the $\mathrm{HIF}-1 \alpha$ protein during hypoxia [43]. CYC1 is a phosphoprotein and subunit of ubiquinol cytochrome $c$ reductase that binds heme groups [43].

The mechanism of oxidative phosphorylation with involvement of cytochrome $\mathrm{c}$ in breast cancer seems to be a bit different than in brain tumors. Indeed, the large pool of reduced cytochrome $c$ that increases with cancer aggressiveness (Figure 6A,B) suggests that the origin of mitochondrial dysfunction comes from complex IV, the last enzyme in the respiratory electron transport chain of cells. Thus, in contrast to brain tumors, the results for breast cancer would rather suggest dysfunction of the complex IV.

The complex IV contains two hemes, cytochrome $a$ and cytochrome $a_{3}$, and two copper centers, the $\mathrm{Cu}_{\mathrm{A}}$ and $\mathrm{Cu}_{\mathrm{B}}$ centers, and several subunits belonging to the COX family. Complex IV receives an electron from each of four cytochrome $c$ molecules, and transfers them to one dioxygen molecule, converting the molecular oxygen to two molecules of water. In this process, it binds four protons from the inner aqueous phase to make two water molecules, and translocates another four protons across the membrane, increasing the transmembrane difference of proton electrochemical potential which triggers the ATP synthase to provide energy. In addition to providing energy, cytochrome $c$ has other essential role within cells: it is one of the regulators of biosynthesis in lipid synthesis de novo.

\subsection{Lipid Synthesis de Novo}

It is known that certain cytochromes such as P450 enzymes (CYP) are critical in metabolizing polyunsaturated fatty acids (PUFAs) to biologically active, intercellular cell signaling molecules (eicosanoids) and/or metabolizing biologically active metabolites of the PUFA to less active or inactive products. These CYPs possess cytochrome P450 omega hydroxylase and/or epoxygenase enzyme activity [44].

It is possible that cyclooxygenase (COX) overexpression observed in cancers $[45,46]$ is related to disruption in the process of electron transfer from cytochrome $c$. Detailed analysis will be necessary to find correlation between conformations and other alterations in COX subunits and electron transfer from cytochrome $c$. Since COX inhibitors belong to 
the most commonly taken drugs $[47,48]$, further research should focus on understanding the mechanisms of correlation. The origin of mitochondrial dysfunction of complex IV in cancers is still unknown, but our previous results demonstrated that there is a link between lipid reprogramming and the COX family [34] in breast cancerogenesis. These observations led us to hypothesize a role for the cytochrome family in mechanisms of lipid reprogramming that regulate cancer progression.

To better understand the link between lipid metabolism and mitochondrial function of cytochrome $c$, let us look once again at the main pathways described in the Scheme 1A.

Pyruvate generated from glycolysis is changed into the compound known as acetylCoA. The acetyl-CoA enters the tricarboxylic acid (TCA) cycle, resulting in a series of reactions. The first reaction of the cycle is the condensation of acetyl-CoA with oxaloacetate to form citrate, catalyzed by citrate synthase. One turn of the TCA cycle is required to produce four carbon dioxide molecules, six NADH molecules and $2 \mathrm{FADH}_{2}$ molecules. The TCA cycle occurs in the mitochondria of the cell. Citrate from the TCA cycle is transported to cytosol and then releases acetyl-CoA by ATP-citrate lyase (ACLY). The resulting acetyl-CoA is converted to malonyl-CoA by acetyl-CoA carboxylases. Then, fatty acid synthase (FASN), the key rate-limiting enzyme in de novo lipogenesis (DNL), converts malonyl-CoA into palmitate, which is the first fatty acid product in DNL. Finally, palmitate undergoes the elongation and desaturation reactions to generate the complex fatty acids, including stearic acid, palmitoleic acid and oleic acid, which we can observe by Raman imaging as lipid droplets (LD). We showed that the lipid droplets are clearly visible in Raman images and we analyzed the chemical composition of LD in cancers $[6,49]$.

Figure 9 shows the normalized Raman intensities at $1444 \mathrm{~cm}^{-1}$ corresponding to vibrations of lipids in human normal and cancer tissues and in lipid droplets in single cells in vitro as a function of cancer grade malignancy at excitation of $532 \mathrm{~nm}$.

One can see that the intensity of the band at $1444 \mathrm{~cm}^{-1}$ increases with cancer aggressiveness in lipid droplets both in breast and brain single cells in contrast to human cancer tissues. Again, as for Raman biomarkers of cytochrome presented in Figures 6 and 7, the relationship between the concentration of lipids vs. aggressiveness is reversed.

To explain this finding, we recall that lipids can be provided by diet or by de novo synthesis. While glioma or epithelial breast cells clearly rely upon fatty acids for energy production, it is not clear whether they acquire fatty acids from the bloodstream or build these carbon chains themselves in de novo lipogenesis. The answer can be provided from comparison between single cells and cancer tissue vs. cancer aggressiveness. Figure 9 shows that in breast and brain tissues, the normalized Raman intensity of fatty acids at $1444 \mathrm{~cm}^{-1}$ decreases, not increases, with increasing cancer grading, in contrast to single cells. It indicates that in tissue, contribution from the bloodstream dominates over de novo fatty acids production. It explains the discrepancies between lipid levels in tissues and in vitro cells vs. cancer aggressiveness presented in Figure 9.

Detailed inspection of Figure 9 demonstrates that for in vitro cell lines, the enhanced lipogenesis (monitored by the Raman peak at $1444 \mathrm{~cm}^{-1}$ ) increases with breast and brain cancer aggressiveness. It is worth emphasizing that enhanced lipogenesis de novo is positively correlated with the concentration of reduced cytochrome $c$ in single breast cells (750, 1126 and $1584 \mathrm{~cm}^{-1}$ in Figure 6). In contrast, the enhanced lipogenesis is inversely related to the concentration of reduced cytochrome $c$ in single brain cells $(750,1126$ and $1584 \mathrm{~cm}^{-1}$ in Figure 7). It indicates that for single cells in vitro, when the extracellular matrix and cell-cell interactions are limited, the lipid de novo biosynthesis increases, whereas oxidative phosphorylation controlled by cytochrome $c$ decreases with increasing cancer aggressiveness. For the situation in the tissues, where the extracellular matrix and cell-cell interactions are not eliminated, the relationship is reversed (Figures 6 and 7). 

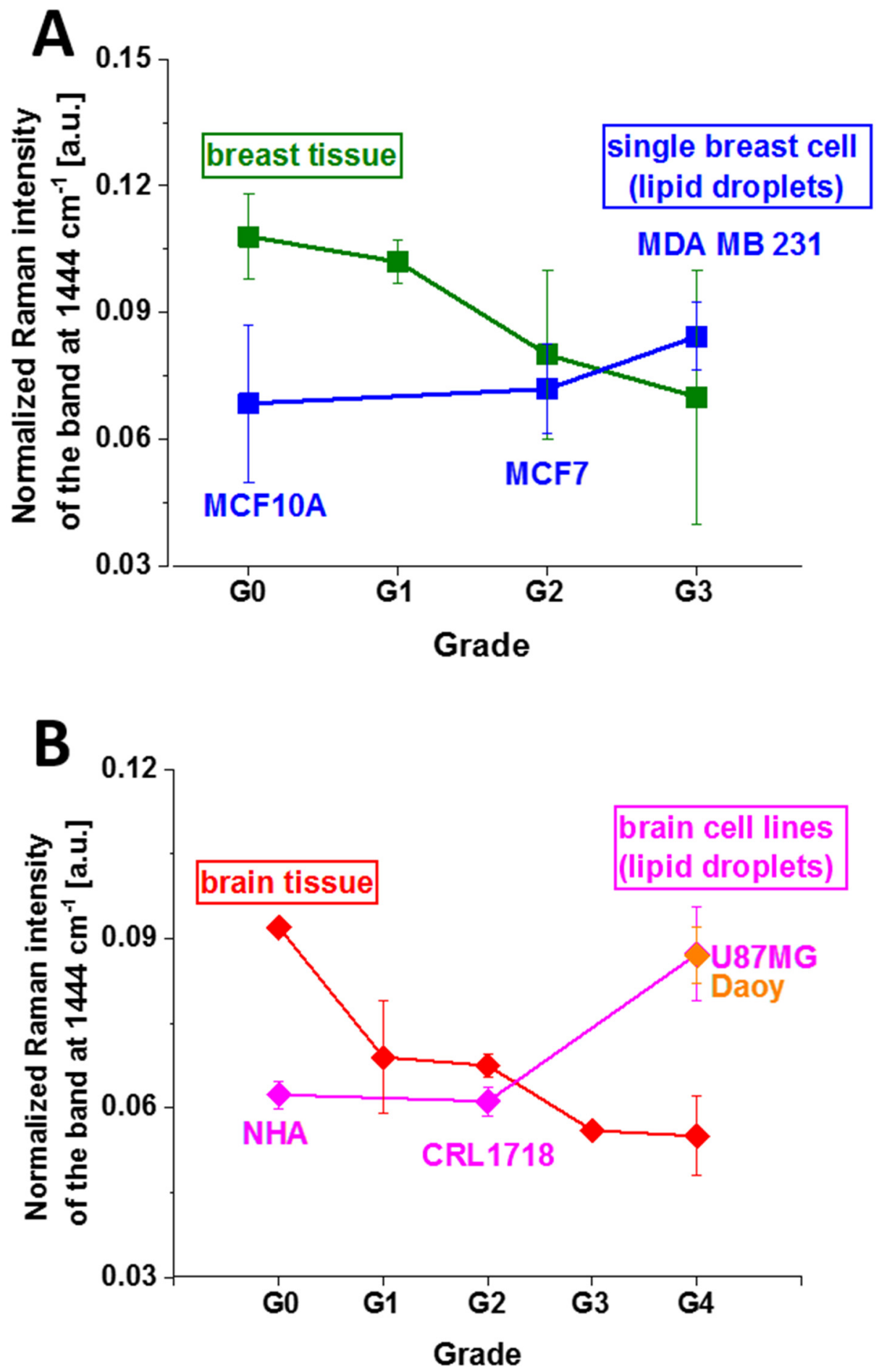

Figure 9. The normalized Raman intensities of lipids in human normal and cancer tissues and cells in vitro at $1444 \mathrm{~cm}^{-1}$ as a function of breast (A) and brain (B) cancer grade malignancy at excitation of $532 \mathrm{~nm}$.

Recently, we found an increased amount of cytoplasmic lipid droplets in the human cancer cells, which must be closely related to increased activity of lipid synthesis in cancerous tissues [49]. We showed that de novo lipogenesis is significantly enhanced in cancer cells [9]. In the de novo mechanism inside cytosol of a cell, fatty acids are shuttled into lipid droplets upon hypoxia in tumors in order to support cell growth and survival upon re-oxygenation [50]. Increasingly, it is appreciated that fatty acids can act as critical bio-energetic substrates within many cancers, including the glioma cell [41]. 
Two types of lipid droplets in normal astrocytes and cancer cells of glioblastoma with distinct chemical compositions, biological functions and vibrational properties have been found [49]. Two types of lipid droplets are related to different functions-energy storage and signaling. Their expression and biochemical composition depend on cancer aggressiveness. The cancer cells are dominantly filled with TAGs and are involved in energy storage. The normal cells are mainly filled with retinyl esters and retinol-binding proteins and are involved in signaling, especially JAK2/STAT6 pathway signaling. The TAG are dominated by polyunsaturated fatty acids (PUFAs) identified as arachidonic acid esters (AA) [51]. Cyclooxygenases (COX) catalyze the conversion of the free essential fatty acids to prostanoids. Prostanoids represent a subclass of eicosanoids consisting of: the prostaglandins (mediators of inflammatory and anaphylactic reactions), the thromboxanes (mediators of vasoconstriction) and the prostacyclins (active in the resolution phase of inflammation) [34].

The deficiency of complex IV containing COX units and related to electron transfer along complex III-cytochrome $c$-complex IV may control and enhance inflammatory processes that lead to cancer development.

Our results allow to look from a new perspective at the triangle between altered bioenergetics, enhanced biosynthesis and redox balance in cancer development.

To check the shift in glucose metabolism from oxidative phosphorylation to lactate production for energy generation (the Warburg Effect), a well-known metabolic hallmark of tumor cells, we used the Raman peak at $823 \mathrm{~cm}^{-1}$ presented in Figure 10 to detect the presence of the lactic acid.
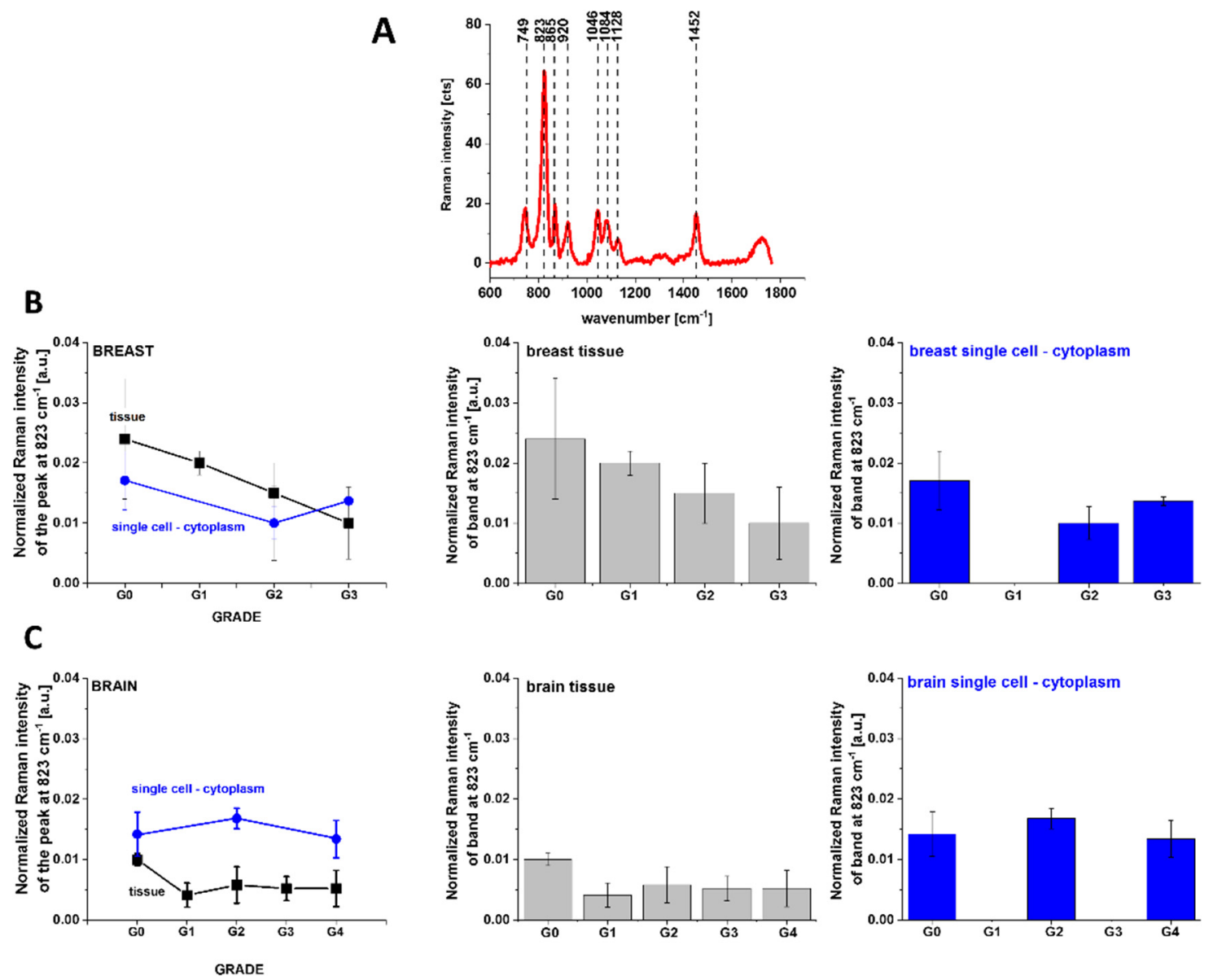

Figure 10. Raman spectrum of lactic acid (A), Raman intensities of peak 823 as a function of human tissue breast cancer malignancy (G1-G3) (B) and of human tumor brain malignancy (G1-G4) (C), with excitation at $532 \mathrm{~nm}$. 
One can see from Figure 10 that the Raman intensity of the band at $823 \mathrm{~cm}^{-1}$ corresponding to the concentration of lactic acid in breast (Figure 10B) and brain (Figure 10C) in cytoplasm and in tissues decreases, not increases, vs. cancer aggressiveness, when compared with the normal brain and breast tissues. It indicates that the efficiency of the switch in glucose metabolism from oxidative phosphorylation to lactate production decreases with cancer aggressiveness. These results combined with the results presented in Figure 6 show that metabolic adaptation in tumors extends beyond the Warburg effect. Indeed, the results from Figure 5 show that concentration of one of the most important molecules in oxidative phosphorylation-cytochrome $c$-in mitochondria increases with breast cancer aggressiveness.

The results suggest that the metabolic adaptation in tumors follow the same pattern of behavior as in normal cells by inducing mechanism of higher cytochrome $c$ concentration to maintain oxidative phosphorylation. The path of oxidative phosphorylation is needed to maintain enhanced biosynthesis, including ATP and de novo fatty acids' production. We showed that de novo fatty acids' production detected by the Raman intensity at $1444 \mathrm{~cm}^{-1}$ increases with cancer aggressiveness, in contrast to the production of lactic acid detected by the Raman intensities at $823 \mathrm{~cm}^{-1}$ that decreases with cancer aggressiveness for single cancer cells in vitro. Based on the Raman intensities of the vibrations corresponding to cytochrome $c$, fatty acids and lactic acid, we discovered that in breast cancer cells, the total ATP turnover was $75 \%$ oxidative and $25 \%$ glycolytic. Presently, an increasing number of reports have supported our results about metabolic regulation in cancers $[41,52,53]$, showing that metabolic adaptation in tumors is highly oxidative. Recently, it was discovered that in MCF-7 breast cancer cells, the total ATP turnover was $80 \%$ oxidative and $20 \%$ glycolytic [54]. This hypothesis was also tested in primary-cultured human glioblastoma cells, and it was found that cells were highly oxidative and largely unaffected by treatment with glucose or inhibitors of glycolysis [5]. Thus, it appears that oxidative phosphorylation can not only co-exist with aerobic glycolysis and lactate release, but it dominates metabolic adaptation in tumors.

The studies presented in this manuscript focus on the application of Raman imaging to monitor changes in the redox state of the mitochondrial cytochromes as a competitive clinical diagnostic tool for cancer diseases involving mitochondrial dysfunction. In order to produce a comprehensive understanding of the role of cytochrome $c$ or $b$ in dysregulation of metabolism, future analysis should be performed by biological validation assays.

\section{Conclusions}

The results suggest that Raman spectroscopy, in the future, could be an alternative technique for monitoring the relations between altered bioenergetics, enhanced biosynthesis and redox balance in cancer development. Our results suggest that the shift in glucose metabolism from oxidative phosphorylation to lactate production for energy generation (the Warburg Effect), a well-known metabolic hallmark of tumor cells, is not a dominant mechanism of cancer development. Our results show that the cancer cells follow the same pattern of behavior as normal cells by inducing mechanisms of higher cytochrome $c$ concentration to maintain oxidative phosphorylation in the electron transport chain required to fuel bioenergetics via ATP and enhance de novo biosynthesis of lipids. The Warburg effect by converting glucose to lactate is only an additional mechanism, which is far less efficient in ATP production than oxidative phosphorylation. The efficiency of the Warburg mechanism decreases with increasing tumor aggressiveness. Based on the Raman intensities of the vibrations corresponding to cytochrome $c$, fatty acids and lactic acid, we discovered that in breast cancer cells, the total ATP turnover was $75 \%$ oxidative and $25 \%$ glycolytic.

We showed that Raman imaging provides additional insight into the biology of gliomas and breast ductal invasive cancer, which can be used for non-invasive grading, differential diagnosis, delineation of tumor extent, planning of surgery and radiotherapy and post-treatment monitoring. We used Raman spectroscopy to monitor changes in the redox state of the mitochondrial cytochromes in ex vivo human brain and breast tissues, 
surgically resected specimens of human and in vitro human brain cells of normal astrocytes (NHA), astrocytoma (CRL-1718), glioblastoma (U87-MG) and medulloblastoma (Daoy), and human breast cells of normal cells (MCF 10A), slightly malignant cells (MCF7) and highly aggressive cells (MDA-MB-231) at $532 \mathrm{~nm}$.

Our results show that human breast and brain cancers demonstrate a redox imbalance compared to normal tissues. The reduced cytochrome $c$ is upregulated in cancers. The results of this paper shed light on a largely non-investigated triangle between cytochromes, lipid metabolism and mitochondrial function in the electron transfer chain. The results presented in this paper providing insight into the crosstalk between organelles increases our understanding of mitochondria-driven cancer. In this paper, we explored a hypothesis involving the possible role of redox state of cytochrome $c$ in cancer. We found biochemical modifications in cellular mitochondria, lipid droplets and cytoplasm observed in cancer progression which are caused by redox imbalance.

The biochemical results obtained by Raman imaging showed that human single cells in vitro demonstrate a redox imbalance by upregulation of cytochrome $c$ in breast ductal cancer and a downregulation of cytochrome $c$ in brain tumors. Both breast and brain tumors demonstrate enhanced lipogenesis de novo compared to normal cells.

This paper demonstrates the critical role of the extracellular matrix in mechanisms of oxidative phosphorylation. We showed that the concentration of reduced cytochrome $c$ (monitored at $1584 \mathrm{~cm}^{-1}$ ) is lower in single cancer cells when comparted with the normal cells at in vitro conditions when the effect of microenvironment is eliminated. In contrast, the redox balance shows a reverted trend in the breast cancer and brain tumor tissues when there are interactions with the environment. The concentration of reduced cytochrome $c$ (monitored at $1584 \mathrm{~cm}^{-1}$ ) is significantly higher in cancer tissue when compared with the normal tissue.

Our results suggest that the mechanisms controlling the electron transport chain might be deregulated in cancers. The electron transport, organized in terms of electronegativity, is inhibited between complex III and cytochrome $c$ for isolated breast cells in vitro and between cytochrome $c$ and complex IV in brain cells. This study demonstrated the ability of confocal Raman microscopy to detect apoptosis mediated by cytochrome $c$ release from mitochondria.

The results presented in this paper suggest that the redox-sensitive peak observed at $1584 \mathrm{~cm}^{-1}$ with excitation at $532 \mathrm{~nm}$ is specifically linked to cytochrome $c$ and can be considered to be a "redox state marker" of the ferric low-spin heme in cyt $c$, assigned to the $v_{19}$ mode, vibrations of methine bridges $\left(\mathrm{C}_{\alpha} \mathrm{C}_{\mu}, \mathrm{C}_{\alpha} \mathrm{C}_{\mu} \mathrm{H}\right.$ bonds) and the $\mathrm{C}_{\alpha} \mathrm{C}_{\beta}$ bond.

Our results show that cytochrome $c$ concentration correlates with cancer aggressiveness. The higher concentration of cytochrome $c$ demonstrates high-turnover and more aggressive tumors. Obviously, the greater the damage of cells or tissues, the higher the serum cytochrome $c$ level. Thus, cytochrome $c$ may be a useful clinical biomarker for diagnosing and assessing pathological entities. The results presented may provide a new opportunity in cancer prevention and treatment that involves the cytochrome family. However, further studies are required for supporting this role for cytochrome $c$ and the responsible pattern recognition receptors remain to be discovered.

Author Contributions: Conceptualization, H.A.; methodology, H.A., B.B.-P., J.M.S. and M.K.; investigation, B.B.-P., J.M.S. and M.K.; data curation, H.A., B.B.-P., J.M.S. and M.K.; writing-original draft preparation, H.A.; writing-review and editing, H.A., B.B.-P., J.M.S. and M.K.; funding acquisition, H.A. and J.M.S. All authors have read and agreed to the published version of the manuscript.

Funding: This research was funded by the National Science Centre of Poland (Narodowe Centrum Nauki, grant number UMO-2019/33/B/ST4/01961 and grant number 2018/02/X/NZ3/00590 (Miniatura2, ID 407029)).

Institutional Review Board Statement: The study was conducted according to the guidelines of the Declaration of Helsinki, and approved by the local Bioethical Committee at the Polish Mother's 
Memorial Hospital Research Institute in Lodz (53/216) and by the institutional Bioethical Committee at the Medical University of Lodz, Poland (RNN/323/17/KE/17/10/2017).

Informed Consent Statement: Informed consent was obtained from all subjects involved in the study.

Data Availability Statement: The raw data underlying the results presented in the study are available from Lodz University of Technology Institutional Data Access for researchers who meet the criteria for access to confidential data. The data contain potentially sensitive information. Request for access to those data should be addressed to the Head of Laboratory of Laser Molecular Spectroscopy, Institute of Applied Radiation Chemistry, Lodz University of Technology. Data requests might be sent by email to the secretary of the Institute of Applied Radiation Chemistry: mitr@mitr.p.lodz.pl.

Conflicts of Interest: The authors declare no conflict of interest.

\section{References}

1. Hanahan, D.; Weinberg, R.A. Hallmarks of Cancer: The next Generation. Cell 2011, 144, 646-674. [CrossRef] [PubMed]

2. Boroughs, L.K.; DeBerardinis, R.J. Metabolic Pathways Promoting Cancer Cell Survival and Growth. Nat. Cell Biol. 2015, 17, 351-359. [CrossRef] [PubMed]

3. Qiu, B.; Simon, M.C. Oncogenes Strike a Balance between Cellular Growth and Homeostasis. Semin. Cell Dev. Biol. 2015, 43, 3-10. [CrossRef]

4. Warburg, O. On the Origin of Cancer Cells. Science 1956, 123, 309-314. [CrossRef] [PubMed]

5. Lin, H.; Patel, S.; Affleck, V.S.; Wilson, I.; Turnbull, D.M.; Joshi, A.R.; Maxwell, R.; Stoll, E.A. Fatty Acid Oxidation Is Required for the Respiration and Proliferation of Malignant Glioma Cells. Neuro. Oncol. 2017, 19, 43-54. [CrossRef]

6. Abramczyk, H.; Brozek-Pluska, B.; Jarota, A.; Surmacki, J.; Imiela, A.; Kopeć, M. A Look into the Use of Raman Spectroscopy for Brain and Breast Cancer Diagnostics: Linear and Non-Linear Optics in Cancer Research as a Gateway to Tumor Cell Identity. Expert Rev. Mol. Diagn. 2020, 20, 99-115. [CrossRef] [PubMed]

7. Abramczyk, H.; Imiela, A.; Brozek-Pluska, B.; Kopec, M. Advances in Raman Imaging Combined with AFM and Fluorescence Microscopy Are Beneficial for Oncology and Cancer Research. Nanomedicine 2019, 14, 1873-1888. [CrossRef]

8. Kopec, M.; Imiela, A.; Abramczyk, H. Monitoring Glycosylation Metabolism in Brain and Breast Cancer by Raman Imaging. Sci. Rep. 2019, 9, 166. [CrossRef] [PubMed]

9. Abramczyk, H.; Imiela, A.; Śliwińska, A. Novel Strategies of Raman Imaging for Exploring Cancer Lipid Reprogramming. J. Mol. Liq. 2019, 274, 52-59. [CrossRef]

10. Polis, B.; Imiela, A.; Polis, L.; Abramczyk, H. Raman Spectroscopy for Medulloblastoma. Childs Nerv. Syst. 2018, 34, 2425-2430. [CrossRef]

11. Abramczyk, H.; Imiela, A. The Biochemical, Nanomechanical and Chemometric Signatures of Brain Cancer. Spectrochim Acta A Mol. Biomol. Spectrosc. 2018, 188, 8-19. [CrossRef] [PubMed]

12. Imiela, A.; Polis, B.; Polis, L.; Abramczyk, H. Novel Strategies of Raman Imaging for Brain Tumor Research. Oncotarget 2017, 8, 85290-85310. [CrossRef]

13. Surmacki, J.; Brozek-Pluska, B.; Kordek, R.; Abramczyk, H. The Lipid-Reactive Oxygen Species Phenotype of Breast Cancer. Raman Spectroscopy and Mapping, PCA and PLSDA for Invasive Ductal Carcinoma and Invasive Lobular Carcinoma. Molecular Tumorigenic Mechanisms beyond Warburg Effect. Analyst 2015, 140, 2121-2133. [CrossRef] [PubMed]

14. Beloribi-Djefaflia, S.; Vasseur, S.; Guillaumond, F. Lipid Metabolic Reprogramming in Cancer Cells. Oncogenesis 2016, 5, e189. [CrossRef] [PubMed]

15. Feichtinger, R.G.; Weis, S.; Mayr, J.A.; Zimmermann, F.; Geilberger, R.; Sperl, W.; Kofler, B. Alterations of Oxidative Phosphorylation Complexes in Astrocytomas. Glia 2014, 62, 514-525. [CrossRef] [PubMed]

16. Deighton, R.F.; Le Bihan, T.; Martin, S.F.; Gerth, A.M.J.; McCulloch, M.; Edgar, J.M.; Kerr, L.E.; Whittle, I.R.; McCulloch, J. Interactions among Mitochondrial Proteins Altered in Glioblastoma. J. Neurooncol. 2014, 118, 247-256. [CrossRef]

17. DeHaan, C.; Habibi-Nazhad, B.; Yan, E.; Salloum, N.; Parliament, M.; Allalunis-Turner, J. Mutation in Mitochondrial Complex I ND6 Subunit Is Associated with Defective Response to Hypoxia in Human Glioma Cells. Mol. Cancer 2004, 3, 19. [CrossRef]

18. Eleftheriadis, T.; Pissas, G.; Liakopoulos, V.; Stefanidis, I. Cytochrome c as a Potentially Clinical Useful Marker of Mitochondrial and Cellular Damage. Front. Immunol. 2016, 7, 279. [CrossRef]

19. Chishiki, M.; Takagi, K.; Sato, A.; Miki, Y.; Yamamoto, Y.; Ebata, A.; Shibahara, Y.; Watanabe, M.; Ishida, T.; Sasano, H.; et al. Cytochrome C1 in Ductal Carcinoma in Situ of Breast Associated with Proliferation and Comedo Necrosis. Cancer Sci. 2017, 108, 1510-1519. [CrossRef] [PubMed]

20. Piccoli, C.; Perna, G.; Scrima, R.; Cela, O.; Rinaldi, R.; Boffoli, D.; Capozzi, V.; Capitanio, N. A Novel Redox State Heme a Marker in Cytochrome c Oxidase Revealed by Raman Spectroscopy. Phys. Scr. 2005, 2005, 199. [CrossRef]

21. Jermyn, M.; Mok, K.; Mercier, J.; Desroches, J.; Pichette, J.; Saint-Arnaud, K.; Bernstein, L.; Guiot, M.-C.; Petrecca, K.; Leblond, F. Intraoperative Brain Cancer Detection with Raman Spectroscopy in Humans. Sci. Transl. Med. 2015, 7, 274ra19. [CrossRef]

22. Bergholt, M.S.; Zheng, W.; Ho, K.Y.; Teh, M.; Yeoh, K.G.; So, J.B.Y.; Shabbir, A.; Huang, Z. Fiber-Optic Raman Spectroscopy Probes Gastric Carcinogenesis In Vivo at Endoscopy. J. Biophotonics 2013, 6, 49-59. [CrossRef] [PubMed] 
23. Haka, A.S.; Shafer-Peltier, K.E.; Fitzmaurice, M.; Crowe, J.; Dasari, R.R.; Feld, M.S. Diagnosing Breast Cancer by Using Raman Spectroscopy. Prac. Natl. Aaad. Sci. USA 2005, 102, 12371-12376. [CrossRef] [PubMed]

24. Morimoto, T.; Chiu, L.; Kanda, H.; Kawagoe, H.; Ozawa, T.; Nakamura, M.; Nishida, K.; Fujita, K.; Fujikado, T. Using RedoxSensitive Mitochondrial Cytochrome Raman Bands for Label-Free Detection of Mitochondrial Dysfunction. Analyst 2019, 144, 2531-2540. [CrossRef]

25. Kircher, M.F.; de la Zerda, A.; Jokerst, J.V.; Zavaleta, C.L.; Kempen, P.J.; Mittra, E.; Pitter, K.; Huang, R.; Campos, C.; Habte, F.; et al. A Brain Tumor Molecular Imaging Strategy Using A New Triple-Modality MRI-Photoacoustic-Raman Nanoparticle. Nat. Med. 2012, 18, 829-834. [CrossRef] [PubMed]

26. Abramczyk, H.; Brozek-Pluska, B.; Kopec, M.; Błaszczyk, M.; Radek, M. Redox Imbalance and Biochemical Changes in Cancer by Probing Redox-Sensitive Mitochondrial Cytochromes in Label-Free Visible Resonance Raman Imaging. bioRxiv 2020. [CrossRef]

27. Abramczyk, H.; Surmacki, J.M.; Brozek-Pluska, B. Redox State Changes of Mitochondrial Cytochromes in Brain and Breast Cancers by Raman Spectroscopy and Imaging. bioRxiv 2020. [CrossRef]

28. Abramczyk, H.; Imiela, A.; Brożek-Płuska, B.; Kopeć, M.; Surmacki, J.; Śliwińska, A. Aberrant Protein Phosphorylation in Cancer by Using Raman Biomarkers. Cancers 2019, 11, 2017. [CrossRef]

29. Abramczyk, H.; Imiela, A.; Surmacki, J. Novel Strategies of Raman Imaging for Monitoring Intracellular Retinoid Metabolism in Cancer Cells. bioRxiv 2020. [CrossRef]

30. Strekas, T.C.; Spiro, T.G. Cytochrome c: Resonance Raman Spectra. Biochim. Biophys. Acta (BBA) Protein Struct. 1972, $278,188-192$. [CrossRef]

31. Hu, S.; Morris, I.K.; Singh, J.P.; Smith, K.M.; Spiro, T.G. Complete Assignment of Cytochrome c Resonance Raman Spectra via Enzymic Reconstitution with Isotopically Labeled Hemes. J. Am. Chem. Soc. 1993, 115, 12446-12458. [CrossRef]

32. Abramczyk, H.; Brozek-Pluska, B. New Look inside Human Breast Ducts with Raman Imaging. Raman Candidates as Diagnostic Markers for Breast Cancer Prognosis: Mammaglobin, Palmitic Acid and Sphingomyelin. Anal. Chim. Acta 2016, 909, 91-100. [CrossRef] [PubMed]

33. Abramczyk, H.; Brozek-Pluska, B. Apical-Basal Polarity of Epithelial Cells Imaged by Raman Microscopy and Raman Imaging: Capabilities and Challenges for Cancer Research. J. Mol. Liq. 2017, 245, 52-61. [CrossRef]

34. Abramczyk, H.; Brozek-Pluska, B.; Surmacki, J.; Jablonska-Gajewicz, J.; Kordek, R. Raman “optical Biopsy” of Human Breast Cancer. Prog. Biophys. Mol. Biol. 2012, 108, 74-81. [CrossRef] [PubMed]

35. Brozek-Pluska, B.; Musial, J.; Kordek, R.; Bailo, E.; Dieing, T.; Abramczyk, H. Raman Spectroscopy and Imaging: Applications in Human Breast Cancer Diagnosis. Analyst 2012, 137, 3773-3780. [CrossRef]

36. Abramczyk, H.; Surmacki, J. Antitumor Activity of Dietary Carotenoids, and Prospects for Applications in Therapy. In Carotenoids; John Wiley \& Sons, Ltd.: Hoboken, NJ, USA, 2016; pp. 31-42. ISBN 978-1-118-62222-3.

37. Consani, C.; Bräm, O.; van Mourik, F.; Cannizzo, A.; Chergui, M. Energy Transfer and Relaxation Mechanisms in Cytochrome $c$. Chem. Phys. 2012, 396, 108-115. [CrossRef]

38. Jadasz, J.J.; Kremer, D.; Göttle, P.; Tzekova, N.; Domke, J.; Rivera, F.J.; Adjaye, J.; Hartung, H.-P.; Aigner, L.; Küry, P. Mesenchymal Stem Cell Conditioning Promotes Rat Oligodendroglial Cell Maturation. PLoS ONE 2013, 8, e71814. [CrossRef]

39. Brazhe, N.A.; Treiman, M.; Brazhe, A.R.; Find, N.L.; Maksimov, G.V.; Sosnovtseva, O.V. Mapping of Redox State of Mitochondrial Cytochromes in Live Cardiomyocytes Using Raman Microspectroscopy. PLoS ONE 2012, 7, e41990. [CrossRef]

40. Tumor Grade Fact Sheet-National Cancer Institute. Available online: https://www.cancer.gov/about-cancer/diagnosisstaging/prognosis/tumor-grade-fact-sheet (accessed on 3 December 2020).

41. Strickland, M.; Stoll, E.A. Metabolic Reprogramming in Glioma. Front. Cell Dev. Biol. 2017, 5, 43. [CrossRef]

42. Song, Z.; Xiaoli, A.M.; Yang, F. Regulation and Metabolic Significance of De Novo Lipogenesis in Adipose Tissues. Nutrients 2018, 10. [CrossRef]

43. Bell, E.L.; Klimova, T.A.; Eisenbart, J.; Moraes, C.T.; Murphy, M.P.; Budinger, G.R.S.; Chandel, N.S. The Qo Site of the Mitochondrial Complex III Is Required for the Transduction of Hypoxic Signaling via Reactive Oxygen Species Production. J. Cell Biol. 2007, 177, 1029-1036. [CrossRef]

44. Danielson, P.B. The Cytochrome P450 Superfamily: Biochemistry, Evolution and Drug Metabolism in Humans. Curr. Drug Metab. 2002, 3, 561-597. [CrossRef]

45. Singh, B.; Berry, J.A.; Shoher, A.; Ramakrishnan, V.; Lucci, A. COX-2 Overexpression Increases Motility and Invasion of Breast Cancer Cells. Int. J. Oncol. 2005, 26, 1393-1399. [CrossRef] [PubMed]

46. Qiu, J.; Shi, Z.; Jiang, J. Cyclooxygenase-2 in Glioblastoma Multiforme. Drug Discov. Today 2017, 22, 148-156. [CrossRef] [PubMed]

47. Lichtenstein, D.R.; Wolfe, M.M. COX-2-Selective NSAIDs: New and Improved? JAMA 2000, 284, 1297-1299. [CrossRef]

48. Werler, M.M.; Mitchell, A.A.; Hernandez-Diaz, S.; Honein, M.A. Use of Over-the-Counter Medications during Pregnancy. Am. J. Obstet. Gynecol. 2005, 193, 771-777. [CrossRef] [PubMed]

49. Abramczyk, H.; Surmacki, J.; Kopeć, M.; Olejnik, A.K.; Lubecka-Pietruszewska, K.; Fabianowska-Majewska, K. The Role of Lipid Droplets and Adipocytes in Cancer. Raman Imaging of Cell Cultures: MCF10A, MCF7, and MDA-MB-231 Compared to Adipocytes in Cancerous Human Breast Tissue. Analyst 2015, 140, 2224-2235. [CrossRef] [PubMed]

50. Bensaad, K.; Favaro, E.; Lewis, C.A.; Peck, B.; Lord, S.; Collins, J.M.; Pinnick, K.E.; Wigfield, S.; Buffa, F.M.; Li, J.-L.; et al. Fatty Acid Uptake and Lipid Storage Induced by HIF-1 $\alpha$ Contribute to Cell Growth and Survival after Hypoxia-Reoxygenation. Cell Rep. 2014, 9, 349-365. [CrossRef] [PubMed] 
51. Baenke, F.; Peck, B.; Miess, H.; Schulze, A. Hooked on Fat: The Role of Lipid Synthesis in Cancer Metabolism and Tumour Development. Dis. Model. Mech. 2013, 6, 1353-1363. [CrossRef]

52. Adar, F.; Erecinska, M. Spectral Evidence for Interactions between Membrane-Bound Hemes: Resonance Raman Spectra of Mitochondrial Cytochrome b-C1 Complex as a Function of Redox Potential. FEBS Lett. 1977, 80, 195-200. [CrossRef]

53. Kakita, M.; Kaliaperumal, V.; Hamaguchi, H. Resonance Raman Quantification of the Redox State of Cytochromes b and c In-Vivo and in-Vitro. J. Biophotonics 2012, 5, 20-24. [CrossRef] [PubMed]

54. Guppy, M.; Leedman, P.; Zu, X.; Russell, V. Contribution by Different Fuels and Metabolic Pathways to the Total ATP Turnover of Proliferating MCF-7 Breast Cancer Cells. Biochem. J. 2002, 364, 309-315. [CrossRef] [PubMed] 